\title{
EL RECHAZO EN FRONTERA A LA LUZ DE LOS DERECHOS FUNDAMENTALES
}

\author{
Lucía Rodríguez Duque \\ Máster en Derecho Constitucional en el Centro \\ de Estudios Políticos y Constitucionales \\ Máster de la Abogacía \\ en la Universidad Carlos III de Madrid \\ luciard96@botmail.com
}

\begin{abstract}
«La frontera como barrera de contención consagra la dualidad del miedo, como justificación frente a medidas que exceptúan la legalidad hasta límites imprevisibles, y la violencia como respuesta».
\end{abstract}

Ángeles Solanes CoRELla

\section{INTRODUCCIÓN}

En un mundo fuertemente globalizado como el actual, la creciente interrelación de los distintos países y la intensificación de los flujos migratorios, tanto voluntarios como forzosos, no se ve acompañada por una mayor apertura de las fronteras ni por una superior protección de los derechos fundamentales de los extranjeros. Estas personas, los sujetos más olvidados del Derecho constitucional a pesar del mandato del art. 13 de la Carta Magna española, se enfrentan desde hace años a un régimen jurídico que dificulta aún más la salvaguarda de sus derechos fundamentales: el rechazo en frontera, figura introducida en 2015 en la Ley Orgánica de Derechos y Libertades de los Extranjeros y que trata de ofrecer cobertura legal a la práctica administrativa de las «devoluciones en caliente», reiteradamente denunciada por diversos organismos nacionales e internacionales por vulnerar las normas más básicas de derechos fundamentales y derechos humanos.

Esta democráticamente cuestionable operación es lo que da sentido a este trabajo, cuyo objeto es verificar si la figura del «rechazo en frontera» cumple con los parámetros exigidos por la Constitución y los Tratados 
Internacionales de Derechos Humanos que complementan la parte dogmática del texto constitucional, pues es este plano jurídico, y no el de la discrecionalidad (o arbitrariedad) administrativa, el que rige los derechos fundamentales y libertades públicas de los ciudadanos extranjeros.

Para ello, este estudio ha seguido la siguiente metodología. Tras ofrecer un marco general de la titularidad de derechos fundamentales y libertades públicas por los extranjeros, complejo y ambiguo debido a la laxitud del texto constitucional, se encuadra la figura del rechazo en frontera dentro de las posibles formas de expulsión y denegación de entrada de extranjeros, previstas en la legislación española de extranjería. Asimismo, para comprender el significado de esta figura y el contexto de su nacimiento, se narra el proceso fáctico y jurídico que llevó a su inclusión en la Ley Orgánica de Extranjería, fundamental para conocer el sentido de este. Todo ello permite detectar los aspectos jurídicos más cuestionables y problemáticos, que, en este estudio, se ha entendido que son los vicios concernientes al procedimiento legislativo que incluyó la figura en el ordenamiento, el «concepto operativo de frontera» que asume la misma, la constitución de esta forma de expulsión de una vía de hecho institucionalizada y la vulneración de tres límites del Derecho internacional a la facultad soberana de controlar el flujo migratorio: el principio de no-devolución, la prohibición de expulsiones colectivas y el derecho a un recurso efectivo.

\section{LA TITULARIDAD DE LOS DERECHOS FUNDAMENTALES Y LIBERTADES PÚBLICAS POR LOS EXTRANJEROS EN EL ORDENAMIENTO JURÍDICO ESPAÑOL}

Para determinar si el rechazo en frontera cumple con las exigencias constitucionales, el primer paso es fijar en qué medida el Estado se ve vinculado por los mandatos constitucionales respecto a los ciudadanos extranjeros. Es decir, se trata de delimitar el marco de derechos fundamentales y libertades públicas de los que son titulares los extranjeros, pues ello determinará el límite del legislador y la Administración Pública a la hora de crear y aplicar normas que afecten a los mismos, ya que, como es sabido, los poderes constituidos deben respetar en todo caso el contenido esencial de los derechos fijado por la Constitución Española (art. 53 de la Constitución, desarrollado en la STC 11/1981). Para dibujar este marco debe examinarse conjuntamente la Constitución Española (en adelante, 
CE), los Tratados Internacionales (en adelante TTII) y la jurisprudencia constitucional e internacional.

Así, en primer lugar, se debe acudir al art. $13 \mathrm{CE}$, que configura todo el régimen jurídico de esta materia debido a que es el único artículo constitucional referido expresamente a los extranjeros y está en el título I, rotulado «De los derechos y deberes fundamentales», y dentro de su capítulo I, «De los españoles y los extranjeros» ${ }^{1}$. El artículo, en su apartado primero, afirma que: «Los extranjeros gozarán en España de las libertades públicas que garantiza el presente título en los términos que establezcan los tratados y la ley». Como se puede observar, es un mandato escueto, por lo que su desarrollo por la jurisprudencia constitucional ha sido imprescindible.

Esto debe ser completado por el mandato contenido en el art. 10.2 CE, que ordena interpretar los derechos fundamentales y libertades públicas reconocidos en la Constitución conforme a los Tratados Internacionales de los que España es parte y a las declaraciones de sus respectivos intérpretes supremos.

Además de ser una fuente interpretativa, se debe tener en cuenta que los Tratados Internacionales también imponen un límite en esta materia: la nacionalidad es un motivo prohibido de discriminación ${ }^{2}$. Esto deriva del Pacto Internacional de Derechos Civiles y Políticos (en adelante, PIDCP), así como de la jurisprudencia del TEDH, de los cuales cabe sentar tres consideraciones: en primer lugar, que los extranjeros son titulares del derecho a la igualdad y a la no discriminación; en segundo lugar, que los Estados deben justificar de forma razonable esta diferencia de trato, ofreciendo motivos poderosos, y, en tercer lugar, que la excepción a esta necesidad de justificación es el reconocimiento de derechos políticos y derechos asociados al núcleo duro del Derecho de extranjería (es decir, la libertad de circulación y residencia y el derecho a entrar o a no ser expulsado del territorio del Estado) $)^{3}$.

Una vez sentadas estas bases, es necesario fijar el significado del contenido del art. 13 CE. Una de las cuestiones clave es si la expre-

${ }^{1}$ M. Vidal Fueyo del Camino, «La jurisprudencia del Tribunal Constitucional en materia de Derechos Fundamentales de los extranjeros a la luz de la STC 236/2007», Revista Española de Derecho Constitucional, núm. 85 (2009), p. 357.

${ }_{2}$ M. Díaz CRego, «El derecho a no ser discriminado por razón de nacionalidad: ¿un derecho de los extranjeros?», Revista Española de Derecho Constitucional, núm. 89 (2010), pp. 121-123.

${ }^{3}$ Ibid., p. 150. 
sión «libertades públicas» se refiere también a «derechos fundamentales». Hay autores que consideran que esta controversia carece de sentido pues se soluciona mediante una mera interpretación sistemática: dado que el art. 13.2 excluye explícitamente los derechos políticos de la titularidad de los extranjeros, procede afirmar que la expresión del art. 13.1 se refiere a los derechos fundamentales pues, de lo contrario, no sería necesaria tal precisión ${ }^{4}$. Sin embargo, esto ya fue resuelto por el TC en su Sentencia 107/1984, al afirmar que el art. 13, cuando se refiere a libertades públicas, «no tiene un significado restrictivo», sino que se refiere a todos los derechos y libertades contenidos en el título I de la Constitución. Además, como indica Rubio Llorente, los TTII sobre la materia ratificados por España, en especial el art. 2 DUDH, proclaman que tales derechos deben ser reconocidos a todas las personas sujetas a la jurisdicción del Estado, sin establecer diferenciación alguna entre ciudadanos y extranjeros 5 .

Otro aspecto de vital importancia es esclarecer la intención del constituyente al incluir el inciso final acerca de que los extranjeros gozarán de los derechos que les reconozca la CE «en los términos que establezcan los Tratados y la ley». Esta expresión ha llevado a la jurisprudencia y a la doctrina a debatir sobre si los derechos fundamentales de los extranjeros son de configuración legal. Para dar una respuesta a este interrogante, se debe aludir a una importantísima doctrina sentada en la ya enunciada STC 107/1984: la clasificación tripartita de derechos. Esta clasificación diferencia tres categorías de derechos respecto a su titularidad por los extranjeros, atendiendo principalmente al criterio de la vinculación de cada derecho con la dignidad de la persona. En primer lugar, se hace referencia a los derechos que corresponden por igual a españoles y extranjeros, por ser imprescindibles para garantizar la dignidad humana. En segundo lugar, nombra los derechos que no pueden atribuirse en modo alguno a los extranjeros, o solamente en términos de reconocimiento recíproco en el Estado de origen del extranjero. Finalmente, establece la categoría de aquellos derechos que pertenecen o no a los extranjeros según lo dispongan los TTII y las leyes, de tal manera que es admisible una diferencia de trato con los españoles respecto a su ejercicio.

${ }^{4}$ S. CUAdRÓn Ambite, Extranjeros en frontera. Un estudio jurídico-práctico del reconocimiento protección y límites del derecho de entrada en España, Madrid, Dykinson, 2018, p. 18.

5 F. Rubio LloRente, La forma del poder. Estudios sobre la Constitución, Madrid, Centro de Estudios Políticos y Constitucionales, 2012, p. 1008. 
Uno de los problemas de esta teoría es la inseguridad jurídica que provoca, pues la jurisprudencia no ha establecido con claridad qué derechos pertenecen a cada categoría, sino que ha ofrecido listas ejemplificativas, sin que se puedan ubicar con seguridad los derechos no aludidos por el TC. Así, en la primera categoría (derechos que corresponden por igual a españoles y extranjeros) ha incluido el derecho a la vida, a la integridad física y moral y a la intimidad, y en la tercera categoría (derechos que pertenecen o no a los extranjeros según dispongan las leyes y los TTII) ha aludido a los derechos de asociación, reunión, circulación, residencia y trabajo ${ }^{6}$.

El otro inconveniente que surge de esta clasificación tripartita de derechos es que la misma parece sugerir que los derechos de los extranjeros son de configuración legal, pues en esta misma sentencia el propio TC afirma que «los derechos y libertades de los extranjeros siguen siendo constitucionales, y, por tanto, dotados (dentro de su específica regulación) de la protección constitucional, pero son todos ellos sin excepción, en cuanto a su contenido, derechos de configuración legal [...]». Sin embargo, esto no puede entenderse como que la titularidad de los derechos por los extranjeros depende del legislador, pues la titularidad de estos es otorgada por la propia Constitución en su art. 13.1. Así, esta declaración del TC debe entenderse como que los derechos fundamentales de los extranjeros no son derechos de configuración legal en su totalidad, ya que, aunque necesitan de un desarrollo legislativo para que su contenido y ejercicio se vea concretado, su titularidad está otorgada directamente por la Constitución ${ }^{7}$. En este aspecto, Flores habla de una «titularidad constitucional a priori», consistente en que, a pesar de que las leyes puedan concretar las condiciones en que los extranjeros disfrutan de esos derechos de configuración legal, el legislador debe respetar la titularidad y el contenido asegurados por la Constitución ${ }^{8}$.

En concreto, la STC 236/2007 aclara las limitaciones que tiene el legislador a la hora de condicionar la titularidad y el ejercicio de los derechos fundamentales de los extranjeros. Se trata de una sentencia cuya importancia radica en que se pronuncia sobre si es lícito imponer limitaciones a los derechos de los extranjeros acogiendo como criterio diferenciador la situa-

6 STC $107 / 1984$.

7 S. CUAdRón Ambite, Extranjeros en frontera..., op. cit., p. 20.

${ }^{8}$ F. FLORES, «Igualdad y discriminación en los mecanismos de protección de los derechos fundamentales de los extranjeros», en Discriminación versus diferenciación (Especial referencia a la problemática de la mujer), Valencia, Tirant Lo Blanch, 2004, disponible en www.tirantonline.com (consultado el 24 de mayo de 2019). 
ción de regularidad o irregularidad del extranjero9 ${ }^{9}$, es decir, una circunstancia no aludida en la Constitución que significaría, por tanto, la posibilidad de hacer depender el régimen de derechos fundamentales de los extranjeros de la mayoría parlamentaria del momento ${ }^{10}$. En este aspecto, el TC se pronuncia afirmando que es constitucional el hecho de que el legislador utilice como criterio la situación jurídica de los extranjeros siempre que no vulnere los preceptos o principios constitucionales, pues «la remisión a la ley que contiene el art. 13.1 CE no supone una desconstitucionalización» (FJ 2. ${ }^{\circ}$ ). Por tanto, el legislador tiene dos límites a la hora de condicionar los derechos fundamentales de los extranjeros, que tendrán un mayor o menor alcance dependiendo de a qué grupo de la clasificación tripartita pertenezca el derecho: la dignidad y el contenido esencial del derecho. Además, estas condiciones deberán tener como finalidad la preservación de otros derechos, bienes o intereses constitucionalmente protegidos, respetando el principio de proporcionalidad.

Así, sentadas todas estas consideraciones, queda dibujado el marco general de titularidad de derechos fundamentales por los extranjeros en España. Ello, puesto en conexión con los derechos que se pueden ver afectados por el rechazo en frontera, permite inferir la conclusión que será el punto de partida de este trabajo: a pesar de que, como sentó una sentencia del TSJ de Andalucía, «los extranjeros no son titulares del derecho fundamental a entrar en España ${ }^{11}$, idea reiterada en los TTII en la materia, los extranjeros sí que son innegables titulares del contenido esencial del derecho a la vida, a la integridad, a la libertad y a la tutela judicial efectiva, pues pertenecen al grupo de derechos que, según la clasificación tripartita de derechos, son imprescindibles para garantizar la dignidad humana. Es una realidad jurídica que debe tenerse presente pues, como se demostrará más adelante, el rechazo en frontera es un régimen que no garantiza la salvaguarda de estos derechos fundamentales de los extranjeros.

9 J. M. Goig Martínez, «Tribunal Constitucional y derechos de los extranjeros. Comentario a la reciente jurisprudencia en materia de extranjería», Teoría y Realidad Constitucional, núm. 22 (2008), p. 641.

${ }^{10}$ M. Vidal Fueyo del Camino, «La jurisprudencia del Tribunal Constitucional...», op. cit., p. 365.

${ }^{11}$ STS de Andalucía núm. 182/2013, de la Sala de lo Contencioso Administrativo con sede en Málaga, de 25 de enero de 2013. 


\section{LOS PROCEDIMIENTOS DE EXPULSIÓN DE EXTRANJEROS}

A pesar de que el objetivo de este trabajo es el análisis del rechazo en frontera, antes de estudiar esta figura es conveniente ofrecer una visión general de los procedimientos existentes en la legislación de extranjería que tienen como finalidad impedir la entrada o imponer la salida de extranjeros.

A la hora de su análisis, es adecuada la clasificación que hace Martínez Escamilla dividiendo las salidas en aquellas decididas por procedimientos administrativos (reguladas en la LOEx) y aquellas acordadas en el marco de un proceso penal (reguladas en el $\mathrm{CP})^{12}$. En este trabajo, sin embargo, nos centraremos en las salidas derivadas de procedimientos administrativos, por ser el rechazo en frontera una figura que se desarrolla en el ámbito de la Administración Pública y no en el penal.

\section{Los procedimientos administrativos que ordenan la no entrada o la salida de extranjeros del territorio español}

Retornos o denegaciones de entrada [arts 26.2 y 60 LOEx, en relación con el 28.3.c)]. Consiste en denegar la entrada al extranjero que pretende entrar por puesto fronterizo habilitado, pero no reúne los requisitos establecidos en la legislación de extranjería. Es un procedimiento en el que rigen diversas garantías, como resolución motivada, derecho a la asistencia letrada o derecho a intérprete.

Rechazos en frontera (DA 10. ${ }^{a}$ LOEx). Permite «rechazar» a los extranjeros que sean detectados en la línea fronteriza de la demarcación territorial de Ceuta o Melilla mientras intentan superar los elementos de contención fronterizos para cruzar irregularmente la frontera, con el fin de impedir la entrada ilegal en España.

Expulsiones por infracciones administrativas [arts. 54 y 53.1.a), b), c), d) y f), en relación con el art. 57 LOEx]. La LOEX recoge un conjunto de infracciones administrativas castigadas con la pena de multa que, según el art. 57 LOEx, podrá ser sustituida por la expulsión del territorio nacional

${ }_{12}$ M. Martínez Escamilla, Detención, internamiento y expulsión administrativa de personas extranjeras, Madrid, Proyecto I+D+i Iusmigrante, 2015, p. 33. 
en caso de que la Administración así lo decida, «en atención al principio de proporcionalidad». Una de estas infracciones es encontrarse irregularmente en territorio español [art. 55. 1.b) LOEx], que solo podrá sustituirse por la expulsión de forma excepcional.

Expulsión por antecedentes penales (art. 57.2 LOEx). También constituye causa de expulsión, con el correspondiente procedimiento, el hecho de que el extranjero «haya sido condenado, dentro o fuera de España, por una conducta dolosa que constituya en nuestro país delito sancionado con pena privativa de libertad superior a un año, salvo que los antecedentes penales hubieran sido cancelados». Técnicamente este supuesto no es una infracción, ya que no está incluida en la lista de infracciones que recoge la ley de extranjería, sino una suerte de consecuencia accesoria a la comisión del hecho delictivo, aplicada una vez cumplida la condena ${ }^{13}$.

Expulsión del extranjero imputado o procesado penalmente (art. 57.7 LOEx). En caso de que el extranjero tenga abierto un expediente administrativo de expulsión y, al mismo tiempo, se encuentre procesado o imputado en un procedimiento judicial por delito o falta para el que la Ley prevea una pena privativa de libertad inferior a seis años o una pena de distinta naturaleza, el juez penal puede autorizar la expulsión, excepto en el caso de que exista una causa motivada por la que entienda que debe denegarla.

\section{Devoluciones}

a) Devolución por contravenir la prohibición de entrada [art. 58.3.a) LOEx]. Procede una orden de devolución cuando un extranjero es expulsado y vuelve a España antes de que finalice el tiempo de prohibición de entrada fijado en la expulsión.

b) Devolución por pretender entrar ilegalmente en el territorio español [art. 58. 3.b) LOEx]. El hecho de que un extranjero pretenda entrar ilegalmente en el país es uno de los supuestos en los que la LOEx permite no aplicar el expediente de expulsión para proceder a su devolución. Dentro de este supuesto se consideran incluidos los extranjeros que sean interceptados en la frontera o sus inmediaciones, quienes deberán ser conducidos a una comisaría por las FCSE para que pueda procederse a su identificación y devolución; requiere, además, de las garantías de asistencia jurídi-

${ }^{13}$ M. Martínez Escamilla, Detención, internamiento y expulsión administrativa..., op. cit., p. 35. 
ca y asistencia de intérprete. A efectos de este trabajo, es necesario subrayar que es este procedimiento, el de devolución, el aplicable en aquellos supuestos en los que un ciudadano extranjero es interceptado en la frontera o sus inmediaciones (incluyendo, evidentemente, la frontera de Ceuta y Melilla), con el objetivo de entrar en España por un puesto no habilitado ${ }^{14}$.

\section{La naturaleza de los procedimientos de expulsión. En especial, del rechazo en frontera}

Para concretar la naturaleza de los procedimientos mencionados, resulta clarificador el criterio divisorio de Velasco Caballero, que divide estos procedimientos según el acto jurídico que decide la salida, pues de ello dependerá cómo se puede ejecutar el mismo. En caso de que la decisión de salida la adopte la propia ley, la tarea de la AP es solamente ejecutiva: no se sigue un procedimiento administrativo que finaliza en una resolución, sino que solo tienen lugar los trámites de ejecución forzosa para dar cumplimiento a la consecuencia prevista por la ley. En cambio, si la salida es decidida por la AP, la tarea que realiza la misma es impositiva de gravámenes: es necesario llevar a cabo un procedimiento, que acabará en una resolución ${ }^{15}$.

Sin embargo, el caso del rechazo en frontera es singular, ya que no se trata de un supuesto de ejecución forzosa ni de una salida decidida por la AP; en realidad, es un caso de coacción directa, pues, como se explicará más adelante con mayor detalle, se describe una situación en la que la AP puede utilizar la fuerza para restaurar la situación de legalidad ${ }^{16}$. En este aspecto, se debe señalar que la STSJ de Andalucía, de 26 de febrero de 2010, considera que el objetivo de restablecer la legalidad alterada es excluyente con la característica de ser una medida de carácter punitivo ${ }^{17}$, por lo que se puede afirmar que el rechazo en frontera, dado que persigue aquel fin, no es una medida de carácter punitivo.

${ }^{14}$ Ibid., p. 35.

15 F. Velasco Caballero, «Expulsión administrativa, devolución, retorno y otras "salidas obligatorias”», Revista Aragonesa de Administración Pública, núm. 6 (2003), pp. 311-312.

${ }^{16}$ F. J. BauzÁ Martorell, El uso de la fuerza en Derecho administrativo, Madrid, Iustel, 2019, p. 134.

17 STSJ de Andalucía núm. 926/2010, de la Sala de lo Contencioso Administrativo con sede en Málaga, de 26 de febrero del 2010. 


\section{LA LEGALIZACIÓN DEL RECHAZO EN FRONTERA}

Como se señaló antes, el procedimiento que debía y debe aplicarse ante el supuesto de hecho que prevé el rechazo en frontera, es decir, aquel en que los extranjeros traten de entrar ilegalmente en territorio español (ya sea en Ceuta y Melilla o en cualquier otro lugar de España) es el procedimiento de devolución (art. 58. 2 LOEx). Por ello, hay que remontarse a los precedentes fácticos y jurídicos de los últimos años para comprender el sentido y las razones de la existencia de una figura como el rechazo en frontera, que contempla un supuesto de hecho ya regulado por otro procedimiento, aunque de forma más específica y particular. Además, estudiar el proceso de legalización es necesario para abordar ciertas controversias que surgen en cuanto a su adecuación a los parámetros constitucionales.

\section{Antecedentes: los sucesos de la playa del Tarajal}

La migración a España procedente de Marruecos, especialmente hacia las ciudades de Ceuta y Melilla, ha sido intensa desde los años noventa, habiéndose producido dos crisis migratorias en 2005 y en $2012^{18}$. A lo largo de este tiempo, es decir, mucho antes de la introducción del «rechazo en frontera» en la legislación española, la Administración española, a través de la Guardia Civil, ha venido realizando una práctica administrativa denominada popularmente «devoluciones en caliente», cuyo frecuente uso estaba demostrado por diversas organizaciones no gubernamentales, como Amnistía Internacional ${ }^{19}$, o por el propio Defensor del Pueblo español ${ }^{20}$.

Dicha práctica consistía en una actuación de las Fuerzas y Cuerpos de Seguridad del Estado en la que los cuerpos de seguridad españoles entregaban a las autoridades marroquíes, por vía de hecho, ciudadanos extranjeros que habían sido interceptados en territorio de soberanía española, eludiendo la aplicación del procedimiento establecido legalmente e incumpliendo las garantías reconocidas a nivel internacional ${ }^{21}$.

\footnotetext{
${ }^{18}$ S. CuAdrón Ambite, Extranjeros en frontera..., op. cit., pp. 165-166.

19 Amnistía Internacional, Informe de Amnistía Internacional 2012, 2013, p. 122.

20 Defensor del Pueblo, Informe del Defensor del Pueblo 2012, 2013 p. 148.

${ }^{21}$ Proyecto I+D+i Iusmigrante, «"Expulsiones en caliente": cuando el Estado actúa al margen de la ley», 2014, p. 2.
} 
Estas devoluciones se reducían a lo ya enunciado: se trataba de una práctica, es decir, no estaba regulada en el ordenamiento español. Y, a pesar de que se había estado produciendo durante años sin la oposición e incluso con el apoyo de los distintos Gobiernos (como se verá reflejado más adelante al exponer los argumentos del Ministerio del Interior para defender dicha práctica), los hechos acaecidos en febrero de 2014 llevaron al Gobierno del momento (del Partido Popular) a revestir la práctica de cobertura legal.

El 6 de febrero de 2014, unos 300 inmigrantes subsaharianos llegaron a la playa de El Tarajal, en Ceuta. Aproximadamente un centenar fue interceptado por las fuerzas marroquíes, pero el resto alcanzó el mar. En ese momento, la Guardia Civil española, al percibir que estaban llegando a la costa española y sin activar el protocolo de salvamento, comenzó a disparar armas de fuego, pelotas de goma y gases lacrimógenos contra ellos. Esto tuvo como consecuencia la muerte de quince personas por ahogamiento. Las que sí consiguieron alcanzar la costa española fueron devueltas no a través del correspondiente procedimiento de devolución, sino a través de la práctica de la devolución «en caliente», lo que suponía la falta de todo trámite legal, como su identificación o la comprobación de la existencia de solicitantes de asilo ${ }^{22}$.

La alta publicidad de estos hechos, que causaron gran impacto a nivel tanto nacional como internacional, exigió explicaciones del Ministerio del Interior español.

\section{Los argumentos del Ministerio del Interior para justificar las devoluciones en frontera}

El Ministerio del Interior aludió a tres razones que trataban de defender la legalidad de la actuación de la Administración. En primer lugar, afirmaban que, en aplicación del concepto operativo de frontera, los extranjeros no habían entrado en territorio español; en segundo lugar, dado que los extranjeros entraron ilegalmente por puestos fronterizos no habilitados, no procedía la aplicación de los procedimientos previstos en la legislación española de extranjería; y, en tercer lugar, que estas prácticas se ven recogías en el Acuerdo de readmisión entre España y Marruecos ${ }^{23}$.

22 S. Cuadrón Ambite, Extranjeros en frontera..., op. cit., p. 167.

${ }^{23}$ Ibid., p. 170. 
Así, es en este momento en el que aparece por primera vez el «concepto operativo de frontera», explicado en un informe de la Guardia Civil sobre los hechos del Tarajal ${ }^{24}$, que fue entregado por el Ministerio del Interior al Congreso de los Diputados el 7 de marzo de 2014 ${ }^{25}$. Dicho concepto operativo de frontera supone que, en los hechos acontecidos en la playa de El Tarajal, los extranjeros nunca llegaron a territorio español, pues, en ese caso, la frontera estaba localizada en la línea de guardias civiles, sirviendo los elementos antidisturbios para marcar dicha línea fronteriza ${ }^{26}$. En este mismo informe se sostiene que «la valla interna materializa la línea con la que el Estado, en una decisión libre y soberana delimita, a los solos efectos del régimen de extranjería, el territorio nacional» ${ }^{27}$. Lo cierto es que, como se examinará en el apartado 4.2, este concepto móvil de frontera es contrario a las normas de Derecho internacional sobre delimitación de fronteras.

El segundo argumento es que, en caso de que los inmigrantes entren en territorio español de forma ilegal por puestos fronterizos no habilitados, pueden ser devueltos o expulsados sin aplicar procedimiento administrativo alguno (es decir, en vía de hecho) ${ }^{28}$. La realidad es que, como ya se ha dicho en el apartado 2, son de aplicación, según el caso, el procedimiento de expulsión (art. 57 LOEx) o el de devolución (art. 58.3 LOEx).

El tercer argumento es que las «devoluciones en caliente» están previstas en el Acuerdo de readmisión entre España y Marruecos, realizado en el marco del Plan de Acción para el África subsahariana. Sin embargo, dicho acuerdo no excluye la aplicación de la LOEx, sino que ambas son compatibles $^{29}$. Y por añadidura, el Acuerdo, en su art. 2, contempla un procedimiento con una serie de garantías (identificación, prueba, documentación...) que en ningún caso pueden ser eludidas.

A pesar de que se analizarán con mayor profundidad en el apartado 4, cabe afirmar que estos argumentos utilizados por el Gobierno no sirven para ocultar la ilegalidad de la práctica de las «devoluciones en caliente», por su evidente carencia de fundamento jurídico.

24 Dirección Operativa Adjunta de la Guardia Civil, «Informe de la Guardia Civil de 8 de febrero de 2014, sobre los hechos de la playa de El Tarajal», 2014.

25 Proyecto I+D+i Iusmigrante, «"Rechazos en frontera": ¿frontera sin derechos?», 2015, p. 14.

26 S. CuAdrón Ambite, Extranjeros en frontera..., op. cit., p. 167.

27 Dirección Operativa Adjunta de la Guardia Civil, «Informe de la Guardia Civil de 8 de febrero de 2014», op. cit.

${ }^{28}$ S. Cuadrón Ambite, Extranjeros en frontera..., op. cit., p. 174.

${ }^{29}$ Ibid., p. 176. 


\section{El proceso de legalización de las «devoluciones en frontera»}

Ante esta patente imposibilidad de sustentar la legalidad de las devoluciones en frontera, el Gobierno aprovechó el hecho de que se estaba tramitando la Ley Orgánica de Protección de Seguridad Ciudadana (LOPSC) para introducir una enmienda que regulase un régimen especial para Ceuta y Melilla y, así, otorgar cobertura legal a las devoluciones en caliente.

El procedimiento legislativo que dio lugar a la Ley de Protección de Seguridad Ciudadana había comenzado por un proyecto de ley, es decir, provenía de una iniciativa legislativa del Gobierno. El Anteproyecto fue aprobado por el Gobierno en noviembre de $2013^{30}$. En el apartado I de la exposición de motivos de dicho Anteproyecto se argumenta la necesidad de esta ley en la creciente demanda social de seguridad ciudadana, por lo que en el art. 1 se indica que «esta ley tiene por objeto la regulación de un conjunto plural y diversificado de actuaciones de distinta naturaleza orientadas a la tutela de la seguridad ciudadana, mediante la protección de personas y bienes y el mantenimiento de la tranquilidad de los ciudadanos».

Así, el Proyecto de Ley llega a las Cortes Generales en julio de $2014^{31}$. El día en que concluía el plazo para la presentación de enmiendas parciales al Proyecto, el Grupo Parlamentario Popular presentó una serie de enmiendas entre las que se encontraba el régimen especial para Ceuta y Melilla $^{32}$, es decir, el régimen de rechazo en frontera, que se introduciría en forma de disposición adicional décima en la $\mathrm{LOEx}^{33}$. Con esta forma de operar, como se verá en el apartado 4.1, se vulneraron los requisitos procedimentales constitucionalmente exigidos sobre el mantenimiento de una estrecha conexión material entre la enmienda propuesta y la iniciativa legislativa, así como sobre el trámite de emisión de consultas, dictámenes e informes.

Las enmiendas fueron aceptadas en el procedimiento legislativo debido al voto favorable del Grupo Parlamentario que las propuso, por lo que el trámite siguió en el Senado. La Ponencia designada por la Cámara Alta decidió redactar una nueva versión de la Disposición para hacer explícita

\footnotetext{
${ }^{30}$ BOCG, Congreso, X Leg., Serie A, núm. 105-1, de 25 de julio de 2014, pp. 1 y ss.

${ }^{31}$ Ibid

32 Este régimen particular se justifica en la necesidad de reflejar la singularidad geográfica de ambas ciudades, únicas fronteras terrestres de la UE con África.

33 S. CuAdrón Ambite, Extranjeros en frontera..., op. cit., p. 177.
} 
la garantía del respeto a la normativa en materia de derechos humanos y, específicamente, el derecho de asilo y la protección subsidiaria ${ }^{34}$. Esto, sin embargo, a juicio de numerosa doctrina, resulta contrario e incluso contradictorio con el tipo de rechazo que se regula en el primer apartado ${ }^{35}$.

Finalmente, la LOPSC fue aprobada con los únicos votos favorables del Partido Popular junto a un diputado del PNV, Carlos Salvador, sumando 181 diputados (solo cinco votos más favorables del mínimo necesario para aprobar una ley orgánica) de los 322 presentes en la votación ${ }^{36}$. Esto, unido al hecho de que solo el grupo parlamentario popular votó a favor de la disposición adicional de la LOEx por la que se introducía el rechazo en frontera, y que la ley nació de un proyecto de ley, permite afirmar que es una ley gestada únicamente por el Gobierno (formularon enmiendas a la totalidad prácticamente todos los grupos parlamentarios) ${ }^{37}$, para avalar una práctica (las devoluciones en caliente) que habían puesto en tela de juicio la legalidad de la actuación de la Administración del momento.

\section{Aplicación de la figura del «rechazo en frontera» de la disposición adicional décima de la LOEx}

Así, la LOEx fue reformada por la LOPSC, recogiendo en su disposición adicional décima la siguiente regulación:

«1. Los extranjeros que sean detectados en la línea fronteriza de la demarcación territorial de Ceuta o Melilla mientras intentan superar los elementos de contención fronterizos para cruzar irregularmente la frontera podrán ser rechazados a fin de impedir su entrada ilegal en España.

2. En todo caso, el rechazo se realizará respetando la normativa internacional de derechos humanos y de protección internacional de la que España es parte.

3. Las solicitudes de protección internacional se formalizarán en los lugares habilitados al efecto en los pasos fronterizos y se tramita-

34 J. M. Bilbao Ubillos, «La llamada ley mordaza: la Ley Orgánica 4/2015 de protección de la seguridad ciudadana», Teoría y Realidad Constitucional, núm. 36 (2015), p. 225.

35 R. Vela Díaz, «El sistema de devoluciones automáticas en frontera a debate: la reciente doctrina del Tribunal Europeo de Derechos Humanos en el caso N. D. y N. T. contra España», Revista de Derecho Migratorio y Extranjería, núm. 47 (2018), p. 5.

36 Página web del Congreso de los Diputados, disponible en http://www.congreso.es/portal/page/portal/Congreso/Congreso/Actualidad/Votaciones (consultado el 24 de mayo de 2019).

37 J. M. Bilbao Ubillos, «La llamada ley mordaza...», op. cit., p. 222, nota a pie. 
rán conforme a lo establecido en la normativa en materia de protección internacional».

Por tanto, el supuesto de aplicación es el intento de «superar los elementos de contención fronterizos para cruzar irregularmente la frontera», lo cual, a juicio de la Administración española, en vistas a sus prácticas frecuentes, se produce en los siguientes supuestos: cuando el extranjero ha accedido o ha intentado acceder a Ceuta y Melilla por vía marítima, cuando el ciudadano extranjero es interceptado habiendo accedido o intentando acceder a alguna de las islas, islotes o peñones de soberanía española situados frente a las costas de Marruecos, y cuando el ciudadano extranjero es interceptado habiendo escalado o descendido o intentando escalar o descender las vallas fronterizas ${ }^{38}$.

Estas prácticas, las denominadas «devoluciones en caliente», se siguen produciendo en las mismas condiciones, incluso después de la condena a España por el TEDH en la sentencia del caso N. D. y N. T. del año $2017^{39}$. La única diferencia es que actualmente existe una cobertura legal, aunque, en palabras de Cuadrón Ambite, el hecho de que tengan cobertura legal «no supone necesariamente que se traten de prácticas legales, sino que se encuentran "reguladas legalmente" $»^{40}$. Constituye, a juicio del Proyecto Iusmigrante, «una práctica no solo inmoral, sino también antijurídica» ${ }^{41}$.

$\mathrm{Al}$ análisis de la veracidad de estas afirmaciones es a lo que se dedica el siguiente apartado.

\section{LOS PROBLEMAS CONSTITUCIONALES DEL RECHAZO EN FRONTERA}

\section{El procedimiento legislativo}

\section{A) El uso abusivo de la enmienda legislativa}

Como se indicó en los apartados 2 y 3.4 de este trabajo, la figura del rechazo en frontera fue introducida en la LOEx por la LOPSC. Pero no

38 Proyecto I+D+I Iusmigrante, «"Rechazos en frontera”...», op. cit., p. 12.

39 C. Soler García, «La prohibición de las expulsiones colectivas de extranjeros en la jurisprudencia del Tribunal Europeo de Derechos Humanos; especial referencia al caso de España», Revista General de Derecho Europeo, núm. 45 (2018), p. 155.

${ }^{40}$ S. Cuadrón Ambite, Extranjeros en frontera..., op. cit., p. 182.

${ }^{41}$ Proyecto I+D+I Iusmigrante, «"Rechazos en frontera”...», op. cit., p. 4. 
estaba prevista en la fase de anteproyecto de ley: fue introducida a través de una enmienda presentada por el Grupo Parlamentario Popular, en el último día del plazo para la presentación de enmiendas.

Hay motivos para afirmar que la introducción de esta figura, realizada a través de esa vía, constituyó un uso abusivo de la enmienda parlamentaria. Esto se debe a que no se puede introducir ex novo, a través de una enmienda, un objeto desconectado con la materia de la iniciativa legislativa. En los arts. 109 a 111 del Reglamento del Congreso, sobre la presentación de enmiendas, no se establece ningún requisito material al contenido de las enmiendas, pero el TC, en el FJ 6. ${ }^{\circ}$ de su Sentencia 119/2011, ha declarado que, a pesar de ello, «la necesidad de una correlación material entre la enmienda y el texto enmendado se deriva, en primer lugar, del carácter subsidiario que, por su propia naturaleza, toda enmienda tiene respecto al texto enmendado». Así, «una vez que una iniciativa legislativa es aceptada por la Cámara o Asamblea Legislativa como objeto de deliberación, no cabe alterar su objeto mediante las enmiendas al articulado, toda vez que esta función la cumple, precisamente, el ya superado trámite de enmiendas a la totalidad, que no puede ser reabierto». En su FJ 7. ${ }^{\circ}$ señala que esto es así aun cuando existan razones de urgencia, pues incluso en esos casos «existe la posibilidad de acudir a otros mecanismos, como [...] las tramitaciones legislativas por los procedimientos de urgencia o en lectura única».

El objeto de esta ley, como se señaló en el apartado anterior remitiéndose al art. 1 del Anteproyecto, es la regulación de un conjunto de medidas orientadas a la seguridad ciudadana, para, según el Gobierno, responder a una creciente demanda social (algo, por cierto, desmentido por el CIS) ${ }^{42}$ y adaptarse al transcurso del tiempo, los cambios sociales y las nuevas formas de poner en riesgo dicha seguridad.

Si se considera este fin como el objeto central de la iniciativa legislativa, es difícil afirmar que la enmienda por la que se introduce el rechazo en frontera cumple la exigencia de conexión material, idea con la que coincide Bilbao Ubillos ${ }^{43}$. Para el Gobierno, existe una conexión material en tanto en cuanto la figura del rechazo en frontera pretende reforzar la protección de las fronteras y «clarificar» el régimen jurídico que rige la actuación de las FCSE. Sin embargo, solo mediante un concepto

42 El Barómetro del CIS muestra que el porcentaje de encuestados que consideraba la inseguridad ciudadana como el principal problema del país oscilaba entre 0,0 en julio de 2014 y 0,3 en marzo de 2015.

43 J. M. Bilbao Ubillos, «La llamada ley mordaza...», op. cit., p. 256. 
flexible y peligrosamente expansivo de «seguridad» ${ }^{44}$ se puede mantener que, para reforzarla, es necesaria la introducción de un régimen de expulsión de extranjeros en el que se permita la inaplicación de todo procedimiento administrativo: el mismo nivel de seguridad (o mayor, incluso) se puede garantizar a través de la aplicación del correspondiente procedimiento de devolución.

\section{B) La ausencia de dictámenes preceptivos}

Como se señalaba en apartados anteriores, el art. 22 de la Ley 50/1997, del Gobierno, establece, respecto a la iniciativa legislativa del Gobierno, que el Ministerio competente debe elaborar un anteproyecto acompañado por memorias, estudios e informes que acrediten la necesidad de este y de una memoria económica que contenga la estimación del coste que provocará. Este anteproyecto irá dirigido al Consejo de Ministros, para que decida sobre los ulteriores dictámenes e informes que resulten convenientes.

Las enmiendas, dado que son introducidas una vez el anteproyecto ya se ha convertido en proyecto de ley y está siendo objeto de debate en el Congreso, no son objeto de dichos informes y estudio por parte del Consejo de Ministros, puesto que se entiende, como afirmó el TC en su Sentencia 119/2011, que las enmiendas guardan una estrecha conexión material con el objeto de la iniciativa legislativa y, por tanto, aunque las enmiendas lo modifiquen, se mantiene su núcleo central sobre el cual se han pronunciado los informes.

Sin embargo, conforme a lo señalado en el apartado anterior, es difícil aceptar una conexión material entre el régimen del rechazo en frontera introducido a través de la enmienda y el objeto inicial de la iniciativa legislativa. Esto impide afirmar que la figura del rechazo fuese objeto de estudio por los dictámenes que el Consejo de Ministros consideró procedentes para el resto de la LOPSC: informes del Consejo General del Poder Judicial, el Consejo Fiscal, el Consejo de Estado y la Agencia Española de Protección de Datos ${ }^{45}$.

${ }^{44}$ Como señala J. M. Bilbao UbiLlos, en relación con la Sentencia de la Corte Suprema de Estados Unidos respecto al caso de «los papeles del Pentágono»: «la seguridad nacional es un argumento peligrosamente expansivo, pues es un concepto vago e impreciso».

45 J. M. Bilbao Ubillos, «La llamada ley mordaza...», op. cit., p. 223. 
Dicha elusión es una infracción del derecho parlamentario que priva de una corrección técnica al objeto legislativo ${ }^{46}$. Como señala Bilbao Ubillos, el proyecto de LOPSC ve corregidos varios defectos y excesos detectados en el Anteproyecto por los órganos que fueron consultados, viéndose algunas previsiones depuradas, suavizadas o suprimidas ${ }^{47}$.

Pero, además, supone arrebatar a la sociedad civil la oportunidad de abrir un debate y discusión pública ${ }^{48}$, pues, como señala Rubio Llorente, «es frecuente que, una vez elaborado el primer borrador, el ministro impulsor del proyecto lo comunique a grupos o sectores afectados (sindicatos, colegios profesionales, asociaciones patronales, etc.) y negocie las sugerencias de estos. A veces, incluso, se hace público el borrador preparado, que pasa así a ser discutido por la opinión» ${ }^{49}$. Todo ello, evidentemente, no se produce si la propuesta jurídica se introduce en forma de enmienda, especialmente si se hace el último día del plazo para presentar las mismas.

\section{C) El «rechazo en frontera» como convalidación legislativa}

Dentro de los conflictos que pueden darse entre los poderes constituidos, existe el que se denomina como «convalidación legislativa de disposiciones y actos administrativos ilegales». Boix Palop lo define como «cualquier actuación del legislador que, por medio de la aprobación de una norma con rango de ley, pretenda eliminar o enervar los efectos prácticos de una declaración de ilegalidad ya recaída o por venir sobre una actuación administrativa». A priori, parece que cabe afirmar que la cobertura legal del rechazo en frontera efectuada por la LOPSC encaja perfectamente en esta definición, pero es necesario comprobar pormenorizadamente si cumple los requisitos necesarios para que se pueda calificar de convalidación legislativa. Los factores que deben concurrir para ello son tres ${ }^{50}$.

En primer lugar, debe existir una disposición o acto administrativo ilegal, siendo dicho vicio de imposible subsanación con la legalidad vigente en el momento. Es ese defecto lo que da una razón de existencia a la con-

46 Proyecto I+D+i Iusmigrante, «"Rechazos en frontera”...», op. cit., p. 8.

47 J. M. Bilbao Ubillos, «La llamada ley mordaza...», op. cit., p. 219.

48 Proyecto I+D+i Iusmigrante, «"Rechazos en frontera”...», op. cit., p. 8.

${ }^{49}$ F. Rubio Llorente, La forma del poder..., op. cit., p. 849.

50 A. BoIx PALOP, «Las leyes de convalidación en el ordenamiento constitucional», Revista Española de Derecho Constitucional, núm. 73 (2005), pp. 162 y 163. 
validación legislativa. En el caso del rechazo en frontera, se cumple este requisito al existir una práctica administrativa, las devoluciones en caliente, que conculcaban la legislación de extranjería al suponer la no aplicación del correspondiente procedimiento de devolución.

En segundo lugar, la intención de dejar sin efectos la decisión judicial ya producida o eventual que declare la ilegalidad de dicho acto o práctica administrativa debe ser materializada a través de una ley. Esta exigencia también se cumple en nuestro caso, pues la figura del rechazo en frontera fue introducida en la LOEx a través de la LOPSC.

Como tercer requisito, la finalidad debe ser dejar sin efectos prácticos una declaración judicial de ilegalidad ya producida o inminente. Aunque se pueden citar más casos, basta con señalar que esta exigencia se ve cumplida con la STEDH del caso N. D. y N. T. c. España, de 3 de octubre de 2017, en la que se analizan las devoluciones en caliente de dos migrantes subsaharianos producidas en 2014, y en la que se condena a España por violación de los arts. 13 (derecho a un recurso efectivo) y 4 del Protocolo núm. 4 (prohibición de expulsión colectiva de extranjeros) del CEDH.

Cabe decir, por tanto, que el otorgamiento de cobertura legal a las devoluciones en caliente a través de la figura del rechazo en frontera introducida por la LOPSC es una convalidación legislativa.

Pero, dentro de este fenómeno, existen dos categorías: en primer lugar, las que persiguen la subsistencia de la actuación administrativa viciada y, en segundo lugar, las que persiguen la subsistencia del contenido material de la actuación ${ }^{51}$. La convalidación legislativa de las devoluciones en caliente es del segundo tipo, pues trata de salvar la ilegalidad de una actuación asumiendo su contenido: el rechazo en frontera simplemente recoge en una ley una práctica administrativa ilegal realizada desde tiempo atrás. Este modelo de convalidación legislativa es, según Boix Palop, radicalmente contrario al derecho español, ya que choca frontalmente con las exigencias de legalidad de la actividad de la Administración recogidas en el arts. 106 y 9.1 de la Constitución, así como con el reconocimiento del derecho a la tutela judicial efectiva del art. $24^{52}$.

En todo caso, hay que señalar que tradicionalmente se entiende que la mera ratificación o legalización de una práctica administrativa entra dentro de la potestad legislativa, lo cual es acorde con la jurisprudencia constitucional en la materia. Pero las previsiones constitucionales, por el

${ }^{51}$ Ibid., pp. 165-167.

52 Ibid., p. 165. 
contrario, sí que imponen límites a las convalidaciones de actos y disposiciones administrativas ilegales. Conforme a la STC 273/2000, el art. 9.3 de la Constitución implica que no es posible una convalidación legislativa de disposiciones sancionadoras no favorables, ni puede amparar una práctica administrativa previa restrictiva de derechos individuales ${ }^{53}$. En este aspecto, por tanto, se puede afirmar que la convalidación legislativa de las devoluciones en caliente no forma parte de las facultades propias de la potestad legislativa, pues se trata de un régimen que recoge una práctica administrativa previa restrictiva de derechos individuales, ya que priva a los extranjeros de los derechos y garantías que les ampararían si fuesen de aplicación los procedimientos que realmente corresponden, es decir, los de expulsión o devolución.

Por último, hay que indicar que esta convalidación no es solo contraria a la Constitución, sino al CEDH. La Sentencia del TEDH del asunto Ruiz Mateos $^{54}$, establece que la convalidación legislativa es contraria al art. 6 del $\mathrm{CEDH}$ en tanto en cuanto el ordenamiento jurídico impida al particular impugnar leyes, ya que se priva al mismo de una posibilidad de defensa suficiente. Esta jurisprudencia se puede aplicar en su totalidad al caso de la convalidación de las devoluciones en caliente pues, antes de que se las dotase de cobertura legal, los extranjeros tenían la posibilidad de interponer recurso administrativo, pero, con la previsión de esta práctica en una ley, están desprovistos de esa facultad.

\section{El concepto operativo de frontera}

Como se señaló en el apartado en que se narraba el proceso de legalización del rechazo en frontera, uno de los argumentos utilizados para justificar la legalidad de las devoluciones en caliente fue el denominado «concepto operativo de frontera», expuesto en un Informe de la Guardia Civil, en el que se razonaba que la práctica administrativa de devolver extranjeros sin aplicar trámite alguno era acorde al ordenamiento español en determinados casos en que se entiende que los extranjeros no han entrado en territorio español y, por tanto, no procede la aplicación de la legislación española. Se trata de un concepto de frontera «retráctil», en palabras del ministro del Interior en su comparecencia al Congreso en febrero

53 Ibid., pp. 175-181.

54 STEDH de 23 de junio de 1993, asunto Ruiz Mateos c. España. 
de 2014, es decir, móvil hacia otros elementos (tales como una valla o una línea de agentes de seguridad) en función de la producción de determinadas circunstancias.

Dado que este concepto se usaba para justificar una práctica administrativa ahora regulada en la ley, podría parecer innecesario analizar la veracidad de este argumento, pero, puesto que el régimen del rechazo en frontera acoge, a efectos prácticos, este concepto de frontera (pues de su regulación se desprende un concepto de frontera variable y desacorde con las normas de Derecho internacional), conviene proceder a su estudio.

Los supuestos en que, a juicio de la Guardia Civil (en el informe citado), no procede la aplicación de la legislación de extranjería española por no haber entrado los extranjeros en territorio español, son tres. El primer caso es aquel en que los inmigrantes entran directamente desde el mar, pues en ese caso, según la Guardia Civil, es de aplicación el protocolo de salvamento: se debe proceder a su rescate y, a continuación, aplicarles el régimen general de extranjería. En segundo lugar, se da el supuesto de que los ciudadanos extranjeros traten de acceder a territorio español a través de la playa, la frontera se retrotrae hasta la barrera de agentes que aguardan en la línea de agua. Y, en tercer lugar, el concepto operativo de frontera se aplica en los supuestos en que la entrada se produzca a través del salto de la valla, el informe sostiene que «la valla interna materializa la línea con la que el Estado, en una decisión libre y soberana, delimita, a los solos efectos del régimen de extranjería, el territorio nacional»; es decir, se entiende que se debe aplicar la legislación española de extranjería solo en el caso de que el extranjero haya traspasado la valla interna ${ }^{55}$.

En todo caso, aunque estas previsiones figuren en un informe de la Guardia Civil, los parámetros con que se juzgue su conformidad a Derecho deben ser los del Derecho internacional, pues las fronteras son un régimen jurídico establecido por la voluntad concordante de dos o más Estados plasmada en un Tratado Internacional, no por la voluntad fluctuante del propio Estado en orden a sus intereses. A dicha fuente convencional hay que añadir, además, la práctica de los órganos legitimados para representar al Estado en la comunidad internacional quienes, a través de actos como declaraciones o demostraciones de aquiescencia, pueden añadir elementos a aspectos no totalmente concretados en los Tratados. Con-

55 M. Martínez Escamilla y J. M. Sánchez Tomás, «Devoluciones ilegales en la frontera sur. Análisis jurídico de las denominadas devoluciones en caliente», en Proyecto $I+D+i$ Iusmigrante, 2015, p. 8. 
forme al art. 26 del Convenio de Viena sobre el Derecho de los Tratados, dichos Tratados y la práctica que los completa no se pueden ver vulnerados por los Estados parte, ni siquiera justificando dicho incumplimiento con base en disposiciones de su derecho interno. Esto es reafirmado por el TEDH en su Sentencia N. D. y N. T. c. España ${ }^{56}$ : «La línea fronteriza entre el Reino de Marruecos y las ciudades de Ceuta y Melilla ha sido delimitada por los Tratados Internacionales en los que son parte los Reinos de España y Marruecos y no puede ser modificada a instancia de uno de estos Estados por las necesidades de una situación concreta de hecho». El TEDH rechaza rotundamente, de esta manera, el concepto operativo de frontera. Asimismo, la jurisprudencia del TS tampoco acoge esta noción de frontera, como señala Cuadrón Ambite ${ }^{57}$ basándose en una sentencia de la Sala de lo Contencioso en que los magistrados utilizan conceptos estrictamente pertenecientes a los Tratados de Derecho internacional ${ }^{58}$.

Así, son los Tratados celebrados entre España y Marruecos sobre la demarcación de su frontera (que ascienden al número de cinco y están datados en la segunda mitad del siglo XIX, siendo el último del año 1891) y la práctica internacional de los órganos representantes de dichos Estados los que configuran el límite del territorio soberano de ambos países, y no las leyes, reglamentos y actos o prácticas administrativas. Es con estos criterios con los que se debe analizar los tres supuestos de aplicación del «concepto operativo de frontera».

Respecto al primer supuesto, que contempla el caso de que los extranjeros entren por mar, no cabe objeción alguna pues se aplica el protocolo de salvamento en la forma en que procede ${ }^{59}$.

En cambio, el segundo caso, relativo a la entrada de extranjeros desde la playa, deben formularse reparos. Conforme al Derecho internacional y al art. 132.2 CE, cualquier playa española, incluyendo las de Ceuta y Melilla, es territorio nacional, así como las aguas de la orilla de estas playas, ya sean aguas interiores o mar territorial.

Asimismo, surgen numerosas réplicas en cuanto a la exigencia de traspasar la valla interna para aplicar la legislación española de extranjería. Pero, debido a la mayor complejidad de este elemento, es necesario hacer referencia a la práctica que ha ido configurando la línea fronte-

${ }^{56}$ STEDH N. D. y N. T. c. España, de 3 de octubre de 2017.

57 S. CuAdrón Ambite, Extranjeros en frontera..., op. cit., p. 172.

58 STS 6218/2003, Sala de lo Contencioso, Sección Sexta, de 13 de octubre.

59 M. Martínez Escamilla y J. M. SÁnchez Tomás (2015): «Devoluciones ilegales en la frontera sur...», op. cit., p. 8. 
riza con Ceuta y Melilla. El Convenio de 1891 realizó una demarcación territorial por medio de mugas, pero posteriormente no se procedió a erigir una verdadera frontera física, ni siquiera tras la independencia de Marruecos en 1956. Esto cambia en 1971 cuando, a raíz de una epidemia de cólera, se instala una verja militar, siguiendo la demarcación original de 1891. Sin embargo, debido al exponencial incremento de la inmigración magrebí dirigida a España, esto se reveló insuficiente, por lo que en 1998 se construyó una doble valla, entre las cuales se creó una «zona de seguridad». En este doble vallado, el exterior sigue la demarcación realizada por la antigua verja militar, es decir, la demarcación trazada en el Convenio de $1891^{60}$.

En 2005, tras un intento de entrada masivo de inmigrantes magrebíes, se decide aumentar la altura de la doble valla, así como instalar una tercera valla y una sirga. El Gobierno español tenía la intención de colocar esta tercera valla y la sirga más allá de la valla exterior, pero Marruecos mostró su radical oposición, al considerar este hecho como una intromisión ilegítima en su territorio. Por ello, el ejecutivo terminó colocando la sirga en la «zona de seguridad» entre ambas vallas ${ }^{61}$.

La inicial posición en la que el Gobierno español quería colocar la tercera valla y la sirga es un factor sobre el que se debe llamar la atención. Es una constatación de que no solo el Gobierno, sino también la oposición, que protestó alegando que se trataba de un «abandono encubierto de territorio español», consideraban que la zona adyacente a la valla exterior pertenecía a la soberanía española. Esta idea del Gobierno se ratifica en sus respuestas a las protestas de la oposición, puesto que este negaba la cesión de territorio español recordando que ya el anterior Gobierno, en 1998, había construido el doble vallado en suelo español, dejando territorio de soberanía española al otro lado del mismo, y en ese momento la oposición no había protestado ${ }^{62}$. De esta manera, el principal argumento utilizado por el Gobierno en $2014{ }^{63}$ para defender la práctica administrativa de las devoluciones en caliente y la no aplicación de la legislación de extranjería española por no estar los extranjeros que escalan la valla o atraviesan la zona de intervallado en territorio español, era radicalmen-

${ }^{60}$ M. Á. Acosta SÁncheZ, «Las fronteras terrestres de España en Melilla: delimitación, vallas fronterizas y tierra de nadie», Revista Electrónica de Estudios Internacionales, núm. 28 (2014), pp. 17-19.

${ }^{61}$ Ibid., pp. 20-22.

${ }^{62}$ Diario de Sesiones del Senado, 24 de abril de 2006, núm. 315.

${ }^{63}$ Del Partido Popular. 
te desmentido por el Gobierno de $1998^{64}$ y por el Gobierno ${ }^{65}$ y oposición de 2006.

Para salvar tal contradicción, los Gobiernos españoles tanto de 2005 como de 2014 han defendido que la zona entre ambas vallas, e incluso la zona que se extiende desde la valla exterior hasta la verja militar, es en efecto un espacio de soberanía española, pero en este espacio no se aplicaría la legislación de extranjería. Esto se debe a que diferencian entre «frontera política» y «frontera geográfica»: el extranjero atravesaría la «frontera geográfica» cuando cruza la verja militar (en caso de que se halle más allá de la valla exterior) o la valla exterior, pero solo atravesaría la «frontera política», y, por tanto, le sería de aplicación la legislación española de extranjería si cruza completamente la valla interior ${ }^{66}$.

En palabras del ministro del Interior en sus declaraciones de 2014 ante el Congreso, esta diferente aplicación de la legislación de extranjería en Ceuta y Melilla estaría justificada «para cumplir el mandato legal [...] precisamente porque Ceuta y Melilla tienen unas características que no tiene ningún otro perímetro fronterizo» de tal manera que «no se puede pretender aplicar la ley de la misma forma en Ceuta y Melilla que en otros lugares que no tienen nada que ver» ${ }^{67}$. Esto, sin embargo, es contrario al art. 96.1 CE y 27 del Convenio de Viena sobre el Derecho de los Tratados, puesto que la frontera está determinada por un Tratado Internacional que no se puede ver vulnerado de forma unilateral por el Estado, y es esta frontera la que fija a partir de qué lugar se debe aplicar el ordenamiento completo de un Estado. Además, vulnera el art. 9.3 de la Constitución, en tanto en cuanto tal arbitrariedad injustificada daña el principio de seguridad jurídica, así como el principio de igualdad en la aplicación de la ley, clave en todo Estado de Derecho.

En este aspecto, hay que señalar que Ceuta y Melilla sí que están sometidas a un régimen especial de inmigración en el marco de la Unión Europea, lo cual se deriva del «doble carácter fronterizo» que adquieren con el Acuerdo Schengen en 1994. Sin embargo, dicho régimen especial afecta al tipo de vigilancia y control de la frontera, a los distintos requisitos para traspasar la frontera en esas ciudades y a las exigencias de recur-

${ }^{64}$ Del Partido Popular.

${ }^{65}$ Del Partido Socialista Obrero Español.

${ }^{66}$ M. Martínez Escamilla y J. M. SÁnchez Tomás, «Devoluciones ilegales en la frontera sur...», op. cit., p. 8, y M. Á. AcostA SÁNCHEZ, «Las fronteras terrestres de España en Melilla...», op. cit., p. 26.

${ }^{67}$ Diario de Sesiones del Congreso de los Diputados, núm. 500, 13 de febrero de 2014. 
sos específicos dirigidos a inmigrantes (esto último, debido a que Ceuta y Melilla, por su carácter aislado y periférico y sus estatutos particulares, son «espacios intersticiales») ${ }^{68}$; en ningún caso este régimen especial derivado del «doble carácter fronterizo» permite una desigual aplicación de la ley en la zona de soberanía española. Sin embargo, a juicio de LópezSala, el Gobierno español ha utilizado una lógica del miedo, mediante sus declaraciones sobre la creciente violencia de los inmigrantes y las crecientes demandas de seguridad por parte de los ciudadanos (antes desmentidas), para «construir una narrativa de caos y crisis transformando a Ceuta y Melilla en enclaves donde se activa un estado de excepción», intentando legitimar, así, medidas que vulneran la legalidad ${ }^{69}$. Acosta Sánchez afirma que «se pretende dar un trato diferenciado a Ceuta y Melilla sin una base legal adecuada e ignorando el principio de igualdad y territorialidad, y en una clara incompatibilidad constitucional» ${ }^{70}$.

Tampoco cabe aludir a una aplicación diferenciada de la ley en Ceuta y Melilla atendiendo a la condición de España como parte de los llamados «Frontlines Member States», es decir, los países fronterizos de la UE que se ven más afectados por la inmigración masiva de inmigrantes (especialmente los países europeos meridionales), pues esta categorización solo hace referencia a las particularidades a las que debe atender el tipo de vigilancia fronteriza de estos Estados ${ }^{71}$.

Por tanto, atendiendo estrictamente a la legalidad vigente, es decir, al Convenio de Viena sobre el Derecho de los Tratados y al Convenio con Marruecos de 1891, se debe afirmar que la zona de soberanía española está determinada por la valla exterior (la zona entre la valla exterior y la verja militar ha sido cedida a Marruecos por aquiescencia española). Esta conclusión es ratificada por Acosta Sánchez, quien explica que, para que una persona entre jurídicamente en España, deben cumplirse dos requisitos: en primer lugar, sobrepasar enteramente la valla exterior (no es suficiente con tocarla por el lado externo) y, en segundo lugar, que el acto de atravesar la valla sea voluntario, sin que colaboren las autoridades españolas (colaboración a veces necesaria en orden a mantener a salvo al migrante). Una vez

${ }^{68}$ A. M. ${ }^{a}$ LÓPEZ-SALA, «La inmigración irregular en Ceuta y Melilla en 2014: prácticas de control y debate público», Anuario CIDOB de la Inmigración en España 2015, Barcelona, CIDOB, 2015, p. 179.

${ }^{69}$ Ibid., p. 187.

${ }^{70}$ M. Á. Acosta SÁnCheZ, «Las fronteras terrestres de España en Melilla...», op. cit., p. 29.

71 A. Del Valle GálveZ, «Los refugiados, las fronteras exteriores y la evolución del concepto de frontera internacional», Revista de Derecho Comunitario Europeo, núm. 55 (2016), pp. 761-777. 
cumplidos estos requisitos, y presente la persona en el espacio intermedio, se encontraría plenamente en zona de soberanía española, ámbito espacial de aplicación del ordenamiento jurídico español en su totalidad ${ }^{72}$.

Este concepto operativo de frontera se ha tratado de trasladar a la LOEx a través del régimen especial para Ceuta y Melilla, estableciendo que «los extranjeros que sean detectados en la línea fronteriza de la demarcación territorial de Ceuta o Melilla mientras intentan superar los elementos de contención fronterizos para cruzar irregularmente la frontera podrán ser rechazados a fin de impedir su entrada ilegal en España». A través de una excesivamente amplia interpretación de los términos «línea fronteriza» y «elementos de contención fronterizos», se trata de trasladar el concepto operativo de frontera a la ley, de tal manera que el rechazo en frontera se aplique cuando un extranjero es interceptado accediendo o intentando acceder a España por vía marítima, por embarcación o a alguna de las playas, islas o islotes, o cuando es interceptado estando presente en la zona de intervallado, encaramado a alguna de las vallas o habiendo descendido totalmente la valla interior ${ }^{73}$. Este tipo de interpretación se ve reflejada en la forma en que se ha aplicado el rechazo en frontera desde que este régimen fue introducido en la legislación en 2015.

Sin embargo, ni siquiera con la disposición aludida es posible aplicar el rechazo en frontera en esos supuestos. Para llegar a tal conclusión, debemos atender a dos elementos: la mención a los elementos de contención fronterizos y la alusión a que la intención de los extranjeros es «cruzar irregularmente la frontera», teniendo la finalidad del rechazo «impedir su entrada ilegal en España». En primer lugar, los «elementos de contención fronterizos» deben estar referidos a estructuras de carácter permanente, las cuales están establecidas solamente en zona fronteriza terrestre, de tal manera que la disposición no se podrá aplicar en caso de que el extranjero trate de llegar por vía marítima o alcance las playas, islas o islotes españoles. En segundo lugar, la exigencia de que el rechazo en frontera se aplica solamente si la intención de los extranjeros es «cruzar irregularmente la frontera» con la finalidad de «impedir su entrada ilegal en España» impide que el rechazo se aplique cuando el extranjero ya está en la zona de intervallado, encaramado a cualquiera de las vallas (salvo al lado externo de la valla exterior, que no es territorio español) o ha traspasado la valla interior, pues en todos estos casos ya está en España y, si se está en España, no se

${ }_{72}$ M. Á. Acosta SÁnCHEZ, «Las fronteras terrestres de España en Melilla...», op. cit., p. 34.

73 Proyecto I+D+I Iusmigrante, «"Rechazos en frontera”...», op. cit., pp. 12-13. 
puede tener la intención de «cruzar irregularmente la frontera» o la finalidad de «impedir la entrada ilegal en España» ${ }^{74}$.

A mayor abundancia, se debe indicar que no solo en esos casos, sino incluso cuando la actuación de las FCSE se realice en territorio marroquí, es de aplicación la legislación española. Este criterio es establecido en la STEDH del caso Hirsi Jamma y otros c. Italia y en la STC 21/1997, en la que el TEDH afirmó que, a pesar de que unos hechos ocurran fuera de cualquier territorio soberano de un Estado parte, es de aplicación el $\mathrm{CEDH}$ sobre toda aquella persona que esté bajo la jurisdicción de un Estado, reconociendo la aplicabilidad extraterritorial del Convenio ${ }^{75}$. Aplicando esta doctrina al caso español, las FCSE deberían aplicar la legislación de extranjería española, aunque les interceptasen en territorio marroquí y, por supuesto, en las playas o islotes de Ceuta y Melilla o en el intervallado, pues la intervención de unas autoridades españoles implica la aplicación de la ley española. Este criterio es seguido en su totalidad por la STC 21/1997, que afirma que los poderes públicos se encuentran sometidos al ordenamiento español no solo cuando actúan en zona de soberanía territorial española, sino también por la mera circunstancia de tratarse de una actividad desarrollada por empleados públicos españoles en el desempeño de sus $\operatorname{cargos}^{76}$.

Por tanto, se puede afirmar que el concepto operativo de frontera es una institución que no tiene reconocimiento en el Derecho nacional ni Internacional, pues vulnera el art. $9 \mathrm{CE}$ en cuanto al principio de legalidad y todas las garantías constitucionales de los extranjeros, así como el art. 96.1 CE respecto a los TTII configuradores de la frontera con Marruecos. Como afirma el Proyecto Iusmigrante, «no existe ningún tipo de norma jurídica que otorgue cobertura legal a un concepto de frontera que pueda ser determinado de forma caprichosa ad casu violando, entre otros elementales principios, el de la prohibición de la arbitrariedad y el de seguridad jurídica» $(9.3 \mathrm{CE})^{77}$.

Así, el concepto operativo de frontera es una manifestación de «la primacía del principio de contención frente al principio de protección en la práctica española de control migratorio», en el marco de las nuevas funciones asumidas por las fronteras y su creciente flexibilidad, en el que los

\footnotetext{
${ }^{74}$ Ibid.

75 STEDH de 27 de febrero de 2012, asunto Hirsi Jamma y otros c. Italia, apartado 74.

76 STC 21/1997, de 10 de febrero, FJ 2.

77 Proyecto I+D+i Iusmigrante, «"Expulsiones en caliente”...», op. cit., p. 7.
} 
escenarios de «excepcionalidad territorial» son cada vez más frecuentes y se ponen al servicio de una política migratoria restrictiva ${ }^{78}$.

\section{El rechazo en frontera como la institucionalización de una vía de hecho}

Ciertas características del rechazo en frontera pueden ser indicios de que dicho régimen supone una institucionalización de una vía de hecho. Por ello, es preciso analizar si la actuación que deriva de la aplicación del rechazo en frontera cumple los requisitos de un acto administrativo legal o es, en cambio, una vía de hecho.

La jurisprudencia constitucional define las vías de hecho como «los actos de los funcionarios y de los agentes de la Administración, faltos de cobertura legal concreta en un título jurídico» ${ }^{79}$ (STC 22/1984, FJ 1). A priori, parece que esta definición descarta la consideración del rechazo en frontera como vía de hecho, pues dicha práctica tiene cobertura legal en la LOPSC. Sin embargo, esto debe ser matizado, debido a las especificidades derivadas del hecho de que el rechazo en frontera es una coacción directa.

En efecto, se debe aclarar que el rechazo en frontera es un supuesto de coacción directa, no de ejecución forzosa. Siguiendo el criterio de García de Enterría y Fernández Rodríguez, según el cual se considera que la ejecución forzosa es un acto administrativo procedimental y la coacción directa un acto administrativo no procedimental (carácter exigido por la imperiosa necesidad de ser ejecutados instantáneamente) ${ }^{80}$, el autor Bauzá Martorell considera que el rechazo en frontera es una coacción directa al tratarse de una regulación que «aplica un efectivo policial después de dirimir in situ una situación de hecho y tomar una decisión, es decir, dictar un acto administrativo que no es fruto de un procedimiento convencional y que no se plasma en documento alguno» ${ }^{81}$.

Dado que se trata de una coacción directa, los factores que se deben examinar para poder concluir si el rechazo en frontera es una práctica administrativa legal o constituye la institucionalización de una vía de

78 A. M. ${ }^{a}$ LóPEZ-SALA, «La inmigración irregular en Ceuta y Melilla...», op. cit., pp. 184-185.

79 STC 22/1984.

${ }^{80}$ E. García de Enterría y T. R. Fernández Rodríguez, Curso de Derecho Administrativo, vols. I y II, Madrid, Civitas, 1989 y 1991, p. 746.

${ }^{81}$ F. J. Bauzá Martorell, El uso de la fuerza en Derecho administrativo, Madrid, Iustel, 2019, p. 134. 
hecho son dos: el principio de legalidad y el principio de proporcionalidad. Son requisitos exigidos no solo a toda forma de coacción direc$\mathrm{ta}^{82}$, sino que aparecen expresamente requeridos en la LOPSC respecto a cualquier medida que suponga una limitación en el ejercicio de las libertades ciudadanas.

\section{A) Principio de legalidad}

Solamente las leyes pueden regular el uso de la fuerza ${ }^{83}$, pues, en términos de Schmitt, «la justificación específica del poder coercitivo del Estado reside en la legalidad» ${ }^{84}$. Pero teniendo en cuenta especialmente el caso del rechazo en frontera, este principio cobra aún más importancia, pues dicho principio adquiere alta relevancia cuando las posibilidades de contravención se acrecientan, en aquellos casos en los que una excesiva flexibilización de los elementos de control difumina los límites de la potestad administrativa y se llega a presuponer la existencia de «apoderamientos generales teleológicamente orientados» ${ }^{85}$.

El rechazo en frontera supone una facultad discrecional, pues la forma en que está configurada («podrán ser rechazados») no vincula una única consecuencia jurídica a un supuesto de hecho, sino que tan solo permite una forma de actuación policial, sin hacerla depender de presupuesto fáctico alguno. Por ello, se debe examinar si dicha figura respeta los límites de la discrecionalidad tal y como son enunciados por García de Enterría ${ }^{86}$ : los elementos reglados, el control de los hechos determinantes y el fin de la potestad discrecional.

1. Elementos reglados. Dentro de los elementos reglados se encuentran la potestad administrativa, la extensión de la potestad y la competencia. Respecto a la potestad administrativa, no se suscita ningún problema, pues la misma se encuentra prevista en la disposición adicional décima de la LOPSC.

82 I. AgirReazkuenaga, La coacción administrativa directa, Madrid, Civitas-Instituto Vasco de Administración Pública, 1990, pp. 334-388.

83 A. Amendola, «La legalità instituzionale», Democrazia y Diritto, 3 (1983), p. 19.

${ }^{84}$ C. Schmit, Legalidad y legitimidad, traducción de J. Díaz García, Madrid, Aguilar, 1971, pp. 5-6.

85 I. AgirReazkuenaga, La coacción administrativa directa, op. cit., pp. 334-335.

${ }^{86}$ E. GarCía de EnTERRía, La lucha contra las inmunidades del poder en el Derecho Administrativo, Madrid, Civitas-Thomson Reuters, 1983, pp. 167-180. 
En cuanto a la extensión de la potestad y la competencia, ambos elementos pueden unificarse en la noción de «vicios de incompetencia» ${ }^{87}$. Los vicios de incompetencia que se producen en el rechazo en frontera son los denominados «vicios esenciales» pues son irregularidades que se originan incluso siguiendo el procedimiento correspondiente ${ }^{88}$. Esto es plausible puesto que la extensión de la potestad debe respetar otro límite señalado por García de Enterría: los principios generales del Derecho, en los que se incluyen los derechos fundamentales. No es suficiente con que la Administración ostente la competencia necesaria y aplique el procedimiento correspondiente, sino que, además, debe actuar conforme a unos «límites implícitos» derivados del conjunto del sistema administrativo y constitucional, pues, en palabras de Sevilla Merino, pueden existir «condiciones constitucionales que vicien la actuación legal de la Administración Pública, incluso llegando a convertirla en vía de hecho» ${ }^{89}$. Por ello, no es posible interpretar las competencias genéricas de forma literal, entendiendo el poder como omnicomprensivo e ilimitado ${ }^{90}$. Una agresión a los principios generales no puede verse justificada por una mera potestad discrecional, pues los principios son los que fundamentan el propio orden jurídico ${ }^{91}$. Esta exigencia no se ve cumplida en el rechazo en frontera pues, aun aplicando el procedimiento previsto en la ley por la autoridad competente, se ponen en peligro o se vulneran los derechos fundamentales a la tutela judicial efectiva, a la vida, a la integridad y a la libertad, por las razones que se explicarán en el último apartado de este trabajo.

Otro aspecto que hay que indicar sobre la competencia es que la laxa y ambigua redacción de la potestad de rechazar en frontera («podrán ser rechazados a fin de impedir su entrada ilegal en España») es insuficiente conforme a las exigencias del principio de legalidad, pues, dado que se trata de una medida que restringe Derechos fundamentales y libertades públicas, su aplicación no puede ser dejada al total arbitrio de la AP, debido al mandato constitucional recogido en el art. 53.1 CE. Incumpliendo la doctrina del TC según la cual, en aras de la protección de los ciudadanos, es posible alterar el orden normal de competencias para afrontar un peligro siempre

${ }^{87}$ I. Sevilla Merino, La protección de las libertades públicas contra la vía de hecho administrativa, Madrid, Civitas, 1992, p. 257.

${ }^{88}$ F. López Menudo, Vía de becho administrativa y justicia civil, Madrid, Civitas, 1998, pp. 179-185.

${ }^{89}$ I. Sevilla Merino, La protección de las libertades públicas..., op. cit., p. 161.

${ }^{90}$ F. López Menudo, Vía de hecho administrativa y justicia civil, op. cit., pp. 176-178.

91 E. García de Enterría, La lucha contra las inmunidades del poder..., op. cit., pp. 176. 
que las medidas no sustituyan en lo indispensable a las autoridades competentes $^{92}$, el rechazo en frontera provoca que esta alteración de las competencias sea permanente, pues, con la laxitud de los términos, permite a la AP fijar cuándo existe ese peligro y cuándo puede utilizar la fuerza.

2. Control de los hechos determinantes. El segundo límite de la técnica de la discrecionalidad está constituido por el control de los hechos determinantes. La aplicación de la potestad discrecional depende de la concurrencia de una realidad de hecho ${ }^{93}$, que, en el caso del rechazo en frontera, además del supuesto de hecho específicamente señalado por la norma (la detección de extranjeros en la línea fronteriza de la demarcación territorial de Ceuta o Melilla mientras intentan superar los elementos de contención fronterizos para cruzar irregularmente la frontera), es la existencia de una situación de urgencia. Esto se debe a que toda coacción directa está caracterizada por la urgencia, ya que el carácter no procedimental del acto administrativo en este caso está justificado por la necesidad de «una rectificación inmediata de una situación dada con la máxima celeridad, sin que se disponga del tiempo indispensable para evitarla por medio de procedimientos ordinarios». Así, la expresión «podrán ser rechazados», se refiere a que, en el caso de que se dé el supuesto de hecho antes señalado (la detección de extranjeros que pretenden cruzar irregularmente), la coacción directa solo se podrá utilizar en el caso de que exista una situación de urgencia ${ }^{94}$.

Agirreazkuenaga afirma que no basta con la simple invocación de la urgencia o el peligro de la seguridad ciudadana para que la acción policial sea lícita, sino que el peligro debe justificarse motivadamente en cada momento para poder aplicar la coacción directa; en este sentido, entiende que existe urgencia cuando se percibe un elemento que perturba o supone un peligro de perturbación grave de la seguridad ciudadana, haciendo necesaria una acción inmediata para mantener o restaurar la seguridad ${ }^{95}$. Por ello, suscita dudas la compatibilidad del precepto que regula el rechazo en frontera con el principio de legalidad y la prohibición de la arbitrariedad de la Administración Pública (art 9.3 CE), ya que, en los términos en los que está redactado, no exige justificación alguna ni impone ningún criterio para apreciar cuándo hay urgencia y, por tanto, concurre el presupuesto habilitante, dejando su valoración y aplicación al arbitrio de la Administración Pública.

${ }^{92}$ STC 33/1982, de 8 de junio.

93 E. García de EnTerría, La lucha contra las inmunidades del poder..., op. cit., p. 170.

${ }^{94}$ I. AgIRREAZKUENAGA, La coacción administrativa directa, op. cit., pp. 261-262.

95 Ibid. 
3. Fin de la potestad discrecional. Constituye el tercer y último límite a las potestades discrecionales enunciado por García de Enterría, quien explica que «las autoridades administrativas cuentan con poderes discrecionales, pero no para el cumplimiento de cualquier finalidad, sino precisamente de la finalidad considerada por la Ley, y en todo caso de la finalidad pública, de la utilidad o interés general» ${ }^{96}$. En el caso del rechazo en frontera, el fin inmediato es impedir la entrada ilegal de extranjeros en España, pero, como se explicó en el apartado 4.1, el fin ulterior de la misma es el objetivo de la ley que la introdujo en el ordenamiento (la LOPSC): la seguridad ciudadana.

Por ello, es necesario hacer referencia a las alusiones constitucionales a la seguridad ciudadana. El art. 104.1 CE, que regula las funciones de las FCSE, establece que las mismas «tendrán como misión proteger el libre ejercicio de los derechos y libertades para garantizar la seguridad ciudadana». Este artículo es un claro reflejo de la doctrina puesta de manifiesto por Grevi, quien afirma que no se pueden restringir las garantías constitucionales de la persona «en nombre de razones más o menos bien definidas de orden público [...], la protección del orden público no es un objetivo que deba alcanzarse a ningún precio, sino que es un valor que debe alcanzarse con respeto a la legalidad constitucional» pues «el orden público democrático se defiende con los instrumentos constitucionales» ${ }^{97}$. A esto hay que añadir que el respeto a los derechos fundamentales y libertades públicas no es solo una nota que debe caracterizar el medio, sino que es el fin ulterior de toda medida policial, pues «la seguridad ciudadana no es un valor en sí misma; [...] solo adquiere relevancia policial en la medida en que implique amenaza, obstáculo o impedimento para el libre ejercicio de los derechos y libertades» ${ }^{98}$.

De esta manera, la figura legal del rechazo en frontera deriva en una actuación administrativa caracterizada por la desviación del poder, ya que solo atiende a una de las vertientes de la seguridad ciudadana (que en este caso se presenta como la vigilancia del cumplimiento de la ley) ignorando completamente la otra (el respeto de los derechos y libertades de los ciudadanos, incluyendo a los extranjeros), siendo esto, una vez más, contrario

${ }^{96}$ I. AgirReazkuenaga, La coacción administrativa directa, op. cit., p. 168.

97 V. GREVI, «Garanzie costituzionali, ordine pubblico e repressione della delinquenza», Il Politico, 1976 pp. 346-348, traducción propia.

98 J. BARCELONA LLOP, «Sobre las funciones y organización de las fuerzas de seguridad: presupuestos constitucionales, problemática jurídica y soluciones normativas», Revista Vasca de Administración Pública, núm. 29 (1991), p. 21. 
al principio de legalidad y sometimiento de la Administración al ordenamiento (arts. 9.3 y 103.1 CE). Es la consecuencia del problema descrito por Agirreazkuenaga, que surge cuando «los límites de las potestades policiales brillan por su ausencia, o se amparan en cláusulas más o menos imprecisas y flexibles como la de orden público, seguridad pública, seguridad ciudadana $[\mathrm{u}]$ orden ciudadano» ${ }^{99}$.

\section{B) Principio de proporcionalidad}

Este principio está enunciado con claridad en la STS de 9 de diciembre de $1985^{100}$ : «[Los funcionarios de policía] pueden y deben recurrir a la fuerza [...] siempre y cuando dicha fuerza o violencia sean $[(1)]$ necesarias, [(2)] los medios adecuados, [(3)] exista una proporción o ecuación entre el mal causado y la índole de la conducta del presunto delincuente o la resistencia por este opuesta, y se hayan agotado los medios pacíficos o las medidas disuasorias» ${ }^{101}$. Por tanto, este principio está compuesto por otros tres subprincipios: el de adecuación o idoneidad, el de necesidad y el de proporcionalidad en sentido estricto.

El principio de adecuación o idoneidad, recogido en el art. 34.2 LPA y en el art. 5.2.c) LOFCS (donde es denominado «principio de congruencia»), es aquel que obliga a que «el acto sirva al fin en consideración al cual la norma ha configurado la potestad que el acto ejercita» ${ }^{102}$, partiendo de la base de que dicho acto debe estar previsto normativamente y motivado por la urgencia ${ }^{103}$. En la regulación analizada, tomando como fin inmediato del rechazo en frontera el impedimento de la entrada ilegal de extranjeros, la medida es indudablemente idónea, pero considerando el fin ulterior, que es la seguridad ciudadana a la par que la protección de los derechos y libertades fundamentales (también de los extranjeros), la medida no se puede considerar adecuada.

Respecto al principio de necesidad, la jurisprudencia del TS indica que para entender que existe necesidad de actuación violenta han de concurrir tales circunstancias que «para el cumplimiento del deber concre-

99 I. AgirReazkuenaga, La coacción administrativa directa, op. cit., pp. 334.

100 STS (Sala 2. ${ }^{a}$ ) de 9 de diciembre de 1985.

${ }^{101}$ La cursiva es mía.

102 E. García de Enterría y T. R. Fernández Rodríguez, Curso de Derecho Administrativo, op. cit., vols. I y II, pp. 512-513.

${ }^{103}$ I. AgirReazkuenaga, La coacción administrativa directa, op. cit., pp. 380-381. 
to en cuyo ámbito está desarrollando su actividad, le sea necesario hacer uso de la violencia, porque, sin tal violencia, no le fuera posible cumplir con la obligación que en ese momento le incumbe» ${ }^{104}$. En el rechazo en frontera, no se puede entender necesaria la medida ni siquiera si se toma como referencia el fin inmediato, pues este consiste en impedir la entrada ilegal de extranjeros en España y en velar por el cumplimiento de la ley, fines ambos que pueden cumplirse si se aplica el procedimiento de devolución del art. 58.3 LOEx.

En tercer y último lugar, en cuanto al principio de proporcionalidad en sentido estricto, que consiste en «obrar de un modo ponderado y prudente en relación con tal gravedad, también conforme a las circunstancias del caso» ${ }^{105}$, de tal forma que se elija, de entre los medios idóneos y adecuados, el menos gravoso, requiere hacer varias consideraciones. Se debe resaltar la importancia de que la obligación de usar el medio más suave o favorable es derivación del principio favor libertatis, que, según el TC, es la expresión del lugar privilegiado que en el orden jurídico constitucional ocupan los derechos fundamentales y libertades públicas, del cual se deriva la obligación de interpretar la ley «en la forma más favorable a la maximización de su contenido», y a interpretar los límites de los derechos fundamentales con criterios restrictivos ${ }^{106}$. Además de esta consideración general, se deben tener en cuenta ciertos criterios, como la gravedad del peligro contra el que se pretende reaccionar (se podrá reaccionar de forma más contundente ante un delito que ante una infracción administrativa) y el valor jurídico de la libertad afectada (cuanto más importante sea la libertad, más grave deberá ser el peligro) ${ }^{107}$.

Aplicando estos criterios al rechazo en frontera, dicha figura no se puede considerar respetuosa con el principio de proporcionalidad: el procedimiento de devolución que, como se ha dicho antes, es el que procede aplicar en realidad, es una medida que permitiría llegar al mismo fin (impedir la entrada ilegal de extranjeros) de una forma mucho menos gravosa (respetando el derecho a la tutela judicial efectiva y demás libertades públicas de todos los extranjeros y ofreciendo la posibilidad de solicitar y adquirir la protección internacional a aquellos que puedan beneficiarse de ella). Es, por ello, una medida totalmente contraria al principio favor libertatis, pues permite negar los derechos y libertades de los extranjeros

\footnotetext{
104 STS (Sala de lo Penal) 4/2015, de 19 de enero.

105 STS 175/1994, de 30 de marzo.

106 SSTC 66/1985, de 13 de mayo, FJ 2, y 159/1986, de 12 de diciembre, FJ 6.

107 I. AgirReazkuenaga, La coacción administrativa directa, op. cit., pp. 382-383.
} 
de forma innecesaria. A esto debe añadirse el criterio de Agirreazkuenaga, quien considera que los derechos fundamentales que gozan de un mayor valor, que son los de la Sección 1. ${ }^{a}$ y, en concreto, el derecho a la vida, a la integridad y a la libertad, solo pueden ceder ante otros bienes igualmente protegidos por la Constitución; conforme a esta forma de efectuar la ponderación, la medida del rechazo en frontera no puede considerarse en ningún modo proporcional, pues supone un sacrificio de los derechos a la vida, a la integridad y a la libertad para evitar una mera infracción administrativa (la entrada ilegal en España no es constitutiva de delito alguno) que no supone ningún peligro para esos mismos derechos de ciudadanos o miembros de las FCSE.

Por todo lo expuesto, el rechazo en frontera puede ser considerado la institucionalización de una vía de hecho, pues supone una regulación que deriva en una actuación administrativa que no respeta el principio de legalidad (incurre en vicios procedimentales, en desviación de poder y en arbitrariedad) ni el principio de proporcionalidad (no se puede considerar idónea, necesaria ni proporcional en sentido estricto), lo que la convierte en una coacción directa que no cumple los requisitos legalmente exigidos para ser un acto administrativo legal resultando, por tanto, en una vía de hecho, incumpliendo los arts. 9.3 y 103.1 CE. Es el corolario de la conclusión que realiza Agirreazkuenaga: «Los medios y/o medidas policiales no cabe justificarlas solo por su utilidad para mantener el orden o la seguridad pública, es decir, que el fin no justifica los medios» ${ }^{108}$.

\section{Límites al control de inmigración por el Estado derivados del Derecho internacional}

Una de las máximas manifestaciones de la soberanía de un Estado es su capacidad para controlar los flujos migratorios que acceden o tratan de acceder a su territorio. Sin embargo, el Derecho internacional de los derechos humanos impone diversos límites a esta potestad estatal. En este trabajo se analizarán, debido a su afectación por la figura del rechazo en frontera, tres normas que están contenidas de forma explícita o implícita en TTII ratificados por España, y que incluso forman parte del Derecho internacional consuetudinario: el principio de no devolución, la prohibición de expulsión colectiva, y el derecho a un recurso efectivo.

${ }^{108}$ Ibid., p. 387. 
En esta limitación del control migratorio por parte del Estado cobra especial relevancia la STEDH del caso N. D. y N. T., antes mencionada, pues la misma aporta criterios para equilibrar los intereses soberanos de los Estados y los derechos humanos de los extranjeros ${ }^{109}$.

\section{A) El principio de no devolución o non-refoulement}

En la esfera del Derecho internacional, uno de los principios que más parece colisionar con la figura del rechazo en frontera es el principio de no devolución o de non-refoulement. Esta regla implica la «obligación de no expulsar, extraditar o rechazar en la frontera a ninguna persona cuya vida o libertad pueda correr peligro como consecuencia del acto de devolución» ${ }^{110}$.

En concreto, las normas que se deben traer a colación son la Convención de Ginebra de 1951 sobre el Estatuto de los Refugiados (en adelante, CG), el CEDH y el PIDCP, que derivan, en esta materia, del art. 14 DUDH. En el caso de que la actuación de las autoridades españolas esté en conexión con el Derecho de la UE, son de aplicación los arts. 18 y 19.1 CDFUE.

La CG establece que es titular del derecho a buscar y recibir asilo la persona que reúna las condiciones para poder ser considerado refugiado. Conforme al art. 1, es refugiado toda aquella persona en que concurra el elemento subjetivo de tener temor a ser perseguida y el elemento objetivo de que ese temor sea fundado ${ }^{111}$. Respecto a estas personas, el art. 33.1 CG proclama la obligación de todo Estado Contratante de no poner en peligro a las mismas a través de la expulsión o devolución a un país donde su vida o su libertad peligre por causas de raza, religión, nacionalidad, pertenencia a determinado grupo social u opiniones políticas. Además de estas circunstancias, para que surja la obligación de no devolución debe existir un nexo entre la expulsión y la potencial vulneración de estos derechos ${ }^{112}$.

109 C. SOlER GarCía, «La prohibición de las expulsiones colectivas...», op. cit., p. 160.

110 L. Peral FernÁndez, «Límites jurídicos al discurso político sobre el control de flujos migratorios: non refoulement, protección en la región de origen y cierre de fronteras europeas», Revista Electrónica de Estudios Internacionales, núm. 11 (2006), p. 5.

111 ACNUR, Manual y directrices sobre procedimientos y criterios para determinar la condición de refugiado, Genève, 2011, p. 12.

112 F. ARLETTAZ, «La expulsión de extranjeros en el Pacto Internacional de Derechos Civiles y Políticos», Boletín mexicano de derecho comparado, vol. 49, núm. 145 (2016), disponible en www.scielo.org. $m x$ /scielo.php?pid=S0041-86332016000100001Escript=sci_arttextEtlng=en. 
Todas estas características se pueden predicar de la obligación de no devolución recogida en la CDFUE, el PIDCP y el CEDH. Sin embargo, el PIDCP y el CEDH tienen la particularidad de que los mismos no proclaman el principio de non-refoulement de forma explícita, sino que ha sido reconocido implícitamente mediante una interpretación sistemática y teleológica del conjunto de la norma realizada por los intérpretes supremos. En el caso del PIDCP, el Comité de Derechos Humanos ha advertido que este principio deriva de los arts. 6 (derecho a la vida) y 7 (prohibición de la tortura y otros tratos crueles, inhumanos y degradantes) del Pacto, que implican la obligación de los Estados parte de no extraditar, expulsar o rechazar a las personas bajo su jurisdicción cuando con ello puedan poner en peligro la vulneración de tales derechos ${ }^{113,114}$. Respecto al CEDH, el TEDH, en el caso Soering c. Reino Unido ${ }^{115}$, estableció que los Estados parte no pueden proceder a la devolución cuando la misma «tenga consecuencias que afecten de modo adverso a los derechos reconocidos en el Convenio» (en 1991, el TEDH extendió esta jurisprudencia a los casos de expulsión, por lo que es aplicable al régimen del rechazo en frontera). Así, el TEDH reconoce el principio de no devolución a través de la interpretación del art. 3, de prohibición de malos tratos: un Estado parte no puede expulsar o extraditar a una persona que esté bajo su jurisdicción si existe el riesgo de que dicha acción derive en un trato contrario al art. 3 de la persona expulsada o extraditada. Es irrelevante que este riesgo exista en un Estado parte o no parte, lo que significa que el TEDH reconoce la eficacia extraterritorial del art. $3^{116}$.

Sin embargo, hay que referirse a un eventual escollo que puede surgir en la puesta en práctica de este principio: el ámbito espacial de aplicación del mismo. Interpretando el art. 1 CG en su literalidad, el principio de no devolución solo se aplica respecto a los refugiados que estén presentes físicamente en el Estado de recepción o en sus fronteras: este argumento puede ser utilizado para negar que constituye un límite del rechazo en frontera.

113 Observación General núm. 31: La indole de la obligación jurídica general impuesta, 80 periodo de sesiones, HRI/GEN/1/Rev.7 at 225 (2004), p. 12; Observación General núm. 20: Artículo 7 Probibición de la tortura u otros tratos o penas crueles, inbumanos o degradantes, 44 periodo de sesiones, HRI/GEN/1/Rev.7 at 173 (1992).

114 F. ARLETTAZ, «La expulsión de extranjeros en el Pacto Internacional...», op. cit.

115 STEDH núm. 14038/88, Soering c. Reino Unido, 1989.

116 A. Salado Osuna, «Los tratos prohibidos en el art. 3 del CEDH», en J. García Roca y P. Santolaya (coords.), La Europa de los Derechos, Madrid, Centro de Estudios Políticos y Constitucionales, 2014, pp. 105-106. 
Sin embargo, existen diversos argumentos para defender una aplicación extraterritorial del principio de no-devolución. En primer lugar, se debe tener en cuenta que el reconocimiento de la condición de refugiado no es constitutivo, sino declarativo: la persona es declarada refugiada porque ya lo es cuando cumple las condiciones fácticas ${ }^{117}$. En segundo lugar, hay que atender a la crítica que realiza el juez Robinson, del TS estadounidense, quien señala que, si el principio de no devolución protege solo a los refugiados que han conseguido acceder al territorio del Estado de destino legal o ilegalmente, y no a aquellos que no han podido entrar, «se está haciendo depender la protección de la Convención de Ginebra de la habilidad del refugiado para acceder clandestinamente al país de asilo y no de la necesidad de protección internacional de la persona» ${ }^{118}$. A esto se debe añadir que este art. 22 prohíbe devolver a los refugiados «en modo alguno»; expresión recogida para prohibir cualquier tipo de devolución que pudiera poner el peligro al individuo ${ }^{119}$. Finalmente, se debe traer a colación el art. 1 del Protocolo de Nueva York de 1967, norma concebida para ampliar el margen de aplicación de la Convención de Ginebra, que prevé que el mismo se aplicará por los Estados Parte «sin limitación geográfica alguna». Es por todas estas razones por las que, respecto a la interpretación del art. 33 de la Convención de Ginebra, ya no se ajusta a la jurisprudencia una aplicación del principio de no devolución limitada al territorio o a las fronteras del Estado ${ }^{120}$.

En el caso del CEDH, dado que su principio de no devolución deriva de una construcción jurisprudencial y no se refiere expresa ni exclusivamente a los refugiados en los términos de la Convención de Ginebra, se trata de una norma que ampara a toda aquella persona que busque protección internacional frente a la tortura y los tratos inhumanos o degradantes y esté bajo la jurisdicción de un Estado parte ${ }^{121}$. Y, conforme a la jurisprudencia del TEDH, la «jurisdicción de un Estado» a la que se refiere el art. $1 \mathrm{CEDH}$ no se limita estrictamente al territorio soberano, sino que, en el caso Loizidou ${ }^{122}$, el TEDH ha señalado que la noción de jurisdicción se

117 ACNUR, Manual y directrices sobre procedimientos... op. cit., p. 10.

118 Sentencia del Tribunal Supremo de los Estados Unidos, Sale c. Haitian Centers, loc. cit., p. 92.

119 J. ABRISKETA URIARTE, «La dimensión externa del derecho de la Unión Europea en materia de refugio y asilo: un examen desde la perspectiva del non-refoulement», Revista de Derecho Comunitario Europeo, núm. 56 (2017), p. 146.

${ }^{120}$ Ibid., p. 151.

${ }^{121}$ Ibid., pp. 138-139.

122 STEDH, Loizidou c. Turquía, 23 de marzo de 1995. 
extiende a todos aquellos actos u omisiones que emanen de los órganos estatales, aunque sea fuera de su territorio ${ }^{123}$.

Por todo ello, se puede afirmar que el principio de no devolución contenido en la CG y en el CEDH constituyen un límite a la regulación y aplicación del rechazo en frontera aunque la misma tenga lugar fuera de las fronteras españolas pues, cuando las autoridades españolas aplican este régimen, están incumpliendo todos los principios más básicos de las normas internacionales en materia de refugio ${ }^{124}$, ya que impiden que las personas merecedoras de protección internacional puedan acceder a ella, poniendo en peligro su vida, su integridad y su libertad. Tal es así que Gortázar Rotaeche incluye el «no rechazo en frontera» como parte del contenido de la obligación de non-refoulement ${ }^{125}$, idea ratificada por el propio ACNUR, que subraya que este principio exige que nadie sea objeto de medidas como la negativa de admisión en la frontera ${ }^{126}$.

\section{B) La prohibición de expulsiones colectivas}

En estrecha relación con el principio de no devolución se encuentra la prohibición de expulsiones colectivas, otra norma de Derecho internacional que podría considerarse como un medio para conseguir el fin que pretende el principio de no devolución. Esto es así debido a la naturaleza de esta prohibición: por una parte, es adjetiva, pues prohíbe la expulsión colectiva de extranjeros sin un examen individual de las circunstancias personales de cada persona; por otra parte, es sustantiva, ya que la expulsión colectiva, aun con el cumplimiento de las exigidas formalidades procedimentales, queda proscrita como política de extranjería ${ }^{127}$.

$\mathrm{Al}$ igual que en el caso del principio de no devolución, la prohibición de expulsiones colectivas se encuentra contenida en diversos TTII de los

123 P. A. Fernández SÁnchez, «El alcance de las obligaciones del CEDH» en J. García Roca y P. Santolaya (coords.), La Europa de los Derechos, Madrid, Centro de Estudios Políticos y Constitucionales, 2014, pp. 50-52.

${ }_{124}$ L. PeRAl FernándeZ, «Límites jurídicos al discurso político...», op. cit., p. 7.

125 C. Gortázar Rotaeche, Derecho de asilo y no rechazo del refugiado, Madrid, Dykinson, 1997, pp. 295-313.

126 Informe del Alto Comisionado de las Naciones Unidas para los Refugiados, Documentos Oficiales de la Asamblea General, 41. ${ }^{\circ}$ periodo de sesiones, Suplemento núm. 12 (A/41/12), Nueva York, 1986, p. 5.

${ }^{127}$ J. F. DuRán Alba, «La interdicción de las expulsiones colectivas de extranjeros», en J. García Roca y P. Santolaya (coords.), La Europa de los Derechos: el Convenio Europeo de Derechos Humanos, Madrid, Centro de Estudios Políticos y Constitucionales, 2014, p. 777. 
que España es parte, de forma explícita o implícita. En el PIDCP se reproduce la forma de reconocimiento del principio de no devolución: la prohibición de expulsiones colectivas no se prevé expresamente, pero el Comité de Derechos Humanos ha declarado que es una obligación derivada de otros derechos, como la prohibición de tratos inhumanos, el respeto de la vida familiar o la no discriminación. Estos derechos solo se pueden asegurar a través de un examen individualizado de la situación de cada persona susceptible de expulsión, extradición o rechazo ${ }^{128}$, es decir, a través de la prohibición de expulsiones colectivas, que un relator especial ha definido como «el acto jurídico por el cual un Estado obliga a una persona o grupo de personas nacionales de otro Estado a abandonar su territorio» ${ }^{129}$.

En cambio, el CEDH sí reconoce expresamente este principio, al afirmar en el art. 4 del Protocolo núm. 4 que «quedan prohibidas las expulsiones colectivas de extranjeros». Para concretar el significado de estos términos, el TEDH ha utilizado una interpretación teleológica, entendiendo que el propósito principal de este artículo es evitar que los Estados puedan expulsar un cierto número de extranjeros sin examinar sus circunstancias personales y, consecuentemente, sin ofrecerles la oportunidad de exponer sus argumentos en contra de esa medida ${ }^{130}$. Con este criterio, en el caso Sultani c. Francia, el Tribunal definió la expulsión colectiva como «toda medida adoptada por las autoridades competentes que obliga a los extranjeros, como grupo, a abandonar un país, salvo en los casos en que dicha medida se adopte al final y sobre la base de un examen razonable y objetivo de la situación particular de cada uno de los extranjeros que forman el grupo» ${ }^{131}$. En cuanto a la aplicación personal del artículo, es decir, qué personas son consideradas «extranjeros» a efectos de la aplicación el mismo, el Tribunal opta por una interpretación amplia, entendiendo como tal a los extranjeros que se encuentran en el territorio, sin distinguir entre si están de paso o si son residentes, refugiados o apátridas; por tanto, no es relevante la situación administrativa en la que se encuentren dichos extranjeros ${ }^{132}$.

${ }^{128}$ F. ARLETTAZ, «La expulsión de extranjeros en el Pacto Internacional...», op. cit.

129 M. KАмто, Informe preliminar sobre la expulsión de extranjeros, A/CN.4/554, 2005, p. 13.

130 Tribunal Europeo de Derechos Humanos, Guía del art. 4 del Protocolo núm. 4 del Convenio Europeo de Derechos Humanos, 2019, p. 5.

${ }_{131}$ SETDH núm. 45223/05, Sultani contra Francia, 20 de septiembre de 2007.

132 Á. SOLANES CORELLA, «Contra la normalización de la ilegalidad: la protección judicial de los extranjeros frente a las expulsiones colectivas y las devoluciones en caliente», Cuadernos Electrónicos de Filosofía del Derecho, núm. 36 (2017), pp. 201-202. 
Así, el factor esencial que debe producirse para que esta prohibición se entienda vulnerada no es de carácter cuantitativo, sino cualitativo. Es irrelevante el número de personas que se expulsen (en el caso Shioshvili se condenó a Rusia por la sola expulsión de una mujer en estado de gestación avanzado con sus cuatro hijos, por no haber tenido en cuenta sus circunstancias personales ${ }^{133}$ ), pues la prohibición se considerará conculcada si no se han cumplido dos exigencias: la realización de un examen individualizado y la puesta en práctica de un procedimiento que ofrezca la posibilidad de alegar argumentos ante autoridades competentes, tomando en consideración las circunstancias personales ${ }^{134}$.

En todo caso, una cuestión controvertida, al igual que en el caso del principio de no devolución, es la de la aplicación territorial de esta prohibición en el marco del CEDH. Sin embargo, este aspecto ha sido aclarado por la propia jurisprudencia del TEDH, que en la Sentencia Hirsi Jamaa, ya aludida en el apartado 4.2, extendió la aplicación del art. 4-P.4, a través de una interpretación expansiva y evolutiva, a los casos en que los migrantes son interceptados por autoridades de Estados parte en el CEDH antes de que entren en el territorio nacional ${ }^{135}$. El TEDH entiende que la realidad de los flujos migratorios ha cambiado (refiriéndose al acceso por vía marítima y a la externalización del control migratorio por los Estados nacionales), por lo que, atendiendo al verdadero fin del art. 4-P4 antes enunciado, acoger una aplicación estrictamente territorial del reduciría notablemente su efecto útil ${ }^{136}$.

Así, una vez sentada la aplicabilidad extraterritorial de este artículo, se puede afirmar que el art. 4-P4 entrará en práctica respecto las actuaciones sobre extranjeros que provengan de órganos estatales en el ejercicio de sus funciones, conforme a la jurisprudencia, ya mencionada anteriormente, del caso Loizidou. A mayor abundancia, este mismo criterio es acogido por la jurisprudencia constitucional española en la STC 21/1997 y por el Informe del Defensor del Pueblo del año $2005^{137}$.

133 STEDH núm. 19356/07, Shiosbvili y Otros c. Rusia, de 20 de diciembre de 2016.

${ }_{134}$ M. Á. Presno LinerA, «Las garantías para los extranjeros y los límites a sus derechos en el Convenio Europeo de Derechos Humanos», Revista del Instituto de Ciencias Jurídicas de Puebla A. C., núm. 21 (2008), p. 94.

135 W. A. SCHABAS, The European Convention of Human Rights: a commentary, Oxford, Oxford University Press, 2015, p. 1079.

136 C. De Castro SÁnchez, «TEDH - Sentencia de 23.02.2012 (Gran Sala), Hirsi Jamaa E.A. c. Italia, 27765/09 - arts. 3 y 13 del CEDH; art. 4 del protocolo núm. 4 - tortura y tratos inhumanos y degradantes - derecho a un recurso efectivo - prohibición de las expulsiones colectivas de extranjeros», Revista de Derecho Comunitario Europeo, núm. 46 (2013), p. 1131.

137 Defensor del Pueblo, Informe del Defensor del Pueblo 2015, 2016, p. 292. 
Por todo ello, se puede afirmar que el rechazo en frontera es una práctica que vulnera la prohibición de las expulsiones colectivas recogi$\mathrm{da}$ en diversos instrumentos internacionales de los que España es parte. Este régimen no cumple con los dos requisitos que exige el TEDH para considerar que una expulsión no vulnera esta prohibición: el rechazo en frontera permite expulsiones sin la realización de un examen individual sobre sus circunstancias personales y sin ofrecer la posibilidad al extranjero de alegar sus argumentos ante una autoridad nacional, pues no se produce procedimiento administrativo o judicial alguno ${ }^{138}$. En este aspecto, es irrelevante que los extranjeros sean interceptados cuando están encaramados a la valla, cuando todavía no han empezado a trepar o cuando están intentando acceder por vía marítima, siempre que estén bajo el control de órganos estatales españoles, pues, como se ha dicho, cabe la aplicación extraterritorial del art. 4. Esta conclusión ha sido acogida por el propio TEDH quien, en la STEDH del caso N. D. y N. T. $c$. España, que conocía de un supuesto de devolución en caliente ocurrido en la frontera española-marroquí (y es considerada no solo un pronunciamiento sobre un caso particular, sino un enjuiciamiento sobre el cariz que está adquiriendo la política del control migratorio en España) ${ }^{139}$, condenó por unanimidad a las autoridades de este país por haber vulnerado el art. 4-P4 CEDH.

\section{C) El derecho a un recurso efectivo}

Fuertemente vinculado con la prohibición de expulsiones colectivas se halla el derecho a un recurso efectivo, ya que es la falta de examen individual de la situación, la omisión de identificación del extranjero y la ausen-

${ }^{138}$ Estas actuaciones, realizadas sobre menores, suponen, además, la vulneración de los arts. 3 (protección del interés superior del niño), 20 (protección y asistencia del Estado en caso de privación del medio familiar) y 37 de la Convención de los Derechos del Niño (prohibición de malos tratos y derecho a la dignidad, libertad y asistencia jurídica). Vid. ComITÉ DE LOS DeRECHOS DEL NiÑo, Dictamen aprobado por el Comité en relación con el Protocolo Facultativo de la Convención sobre los Derechos del Niño relativo a un procedimiento de comunicaciones respecto de la Comunicación núm. 4/2016, 2019.

139 J. M. SÁnchez Tomás, «Las devoluciones en caliente en el Tribunal Europeo de Derechos Humanos: STEDH, N. D. y N. T. c. España, de 3 de octubre de 2017)», Revista Española de Derecho Europeo, núm. 45 (2018), disponible en https://www.ucm.es/datal cont/docs/1413-2018-05-07-STEDH\%20ND\%20y\%20NT_expulsiones\%20expres_S\%C3 por 100A1nchez\%20Tom\%C3 por 100A1s_REDE_2018_digital89.pdf (consultado el 24 de mayo de 2019). 
cia del procedimiento de asilo lo que deriva en la imposibilidad de interponer un recurso efectivo.

Este derecho está proclamado en el art. 8 DUDH, pero encuentra mayor desarrollo en el marco del CEDH, donde está reconocido en su art. 13. Más que un derecho, es una garantía de los demás derechos reconocidos en el mismo, pues consiste en exigir a las autoridades nacionales que aseguren la existencia de un recurso interno que permita a la autoridad nacional competente conocer sustancialmente de la queja de una posible violación del Convenio, así como proporcionar un remedio. Es decir, es el TEDH quien verifica si el recurso establecido por el Estado parte es efectivo ${ }^{140}$.

En esta verificación de la efectividad del recurso, el TEDH ha establecido, a través de su jurisprudencia, una serie de requisitos. Un criterio básico es considerar que el recurso es efectivo solamente si el control ejercido por el juez nacional no es más limitado que el que ejercería dicho Tribunal ${ }^{141}$. Además, este recurso debe posibilitar una investigación efectiva, capaz de identificar y castigar a los responsables, así como una eventual compensación por los hechos ${ }^{142}$, siendo necesario que las sentencias internas firmes sean efectivamente aplicadas ${ }^{143}$.

En todo caso, para que el demandante pueda invocar el art. 13, el mismo debe alegar una «queja discutible o defendible» ${ }^{144}$, que, a pesar de que dependerá de cada caso concreto, consistirá en acreditar un perjuicio importante, sin que sea necesario demostrar una violación previa del Convenio ${ }^{145}$.

Hay que añadir que existe un requisito adicional en determinados casos, lo que se debe subrayar pues guarda estrecha relación con el objeto de este trabajo. El requisito de efectividad del recurso exige prevenir cualquier medida contraria al Convenio cuyos efectos sean potencialmente irreversibles ${ }^{146}$; por esta razón, cuando se ven afectados derechos abso-

140 E. CARmona CUENCA, «El derecho a un recurso efectivo ante una instancia nacional. Problemas interpretativos (art. $13 \mathrm{CEDH}$ )» en J. García Roca y P. Santolaya (coords.), La Europa de los Derechos, Madrid, Centro de Estudios Políticos y Constitucionales, 2014, pp. 566-568.

${ }^{141}$ Ibid.

142 STEDH núm. 7511/13, Husayn (Abu Zubaydab) v. Poland, 14 de julio de 2014.

143 STEDH núm. 31107/96, Iatridis c. Grecia, 1999.

144 Tribunal Europeo de Derechos Humanos, Guide on Article 4 of Protocol num. 4 to the European Convention of Human Rights - Probibition of collective expulsions of aliens, 2019, p. 8.

${ }_{145}$ Á. Solanes CoRella, «Contra la normalización de la ilegalidad...», op. cit., pp. 217-218.

146 Tribunal Europeo de Derechos Humanos, Guide on Article 4 of Protocol núm. 4..., op. cit., p. 9. 
lutos, tales como la vida (art. 2) y los malos tratos (art. 3) es necesario que el recurso tenga efecto suspensivo para considerar que el mismo es efectivo $^{147}$. Pero, para ello, es imprescindible alegar un riesgo real de violación de los derechos amparados por los arts. 2 y 3 CEDH. Este efecto suspensivo es, evidentemente, imposible con la regulación del rechazo en frontera, pues la misma no contempla ningún procedimiento en que el extranjero pueda alegar un riesgo real de vulneración de su derecho a la vida o de prohibición de malos tratos.

Se debe aludir, además, a la posibilidad que ofrece el CEDH de limitar el art. 13 por razones de seguridad nacional; sin embargo, el TEDH ha afirmado que estos límites no deben actuar cuando el art. 3 CEDH está en juego ${ }^{148}$, así como que no se cumplen las garantías mínimas exigidas por el dicho artículo cuando el ejecutivo tiene la facultad de fijar arbitrariamente el concepto de «seguridad nacional» y los tribunales no valoran si el ejecutivo realmente tenía pruebas para demostrar que el extranjero es un riesgo para la seguridad nacional ${ }^{149}$. Circunstancias, ambas, que se dan en la práctica del rechazo en frontera, pues supuestamente, como ya se ha dicho en anteriores apartados, tiene como objetivo proteger una «seguridad ciudadana» cuyo contenido se encuentra al arbitrio de la Administración, la cual, dado que no aplica procedimiento administrativo alguno, no se ve obligada a ofrecer pruebas del peligro que constituye el extranjero rechazado para la seguridad ciudadana de España.

En cuanto a la relación de las expulsiones colectivas con el derecho de asilo, el TEDH se ha pronunciado expresamente sobre los procedimientos sumarios o rápidos para la denegación de asilo, afirmando que son adecuados conforme al art. $13 \mathrm{CEDH}$ siempre y cuando haya un examen de la solicitud ${ }^{150}$, circunstancia que tampoco cumple la regulación del rechazo en frontera.

Son, por tanto, numerosas las razones que apuntan a la vulneración de este derecho por el rechazo en frontera. La ausencia total de cualquier procedimiento que permita la identificación del extranjero y su información sobre los derechos que le asisten desemboca en una imposibilidad de interponer un recurso efectivo. Se suprime la posibilidad de realizar una investigación efectiva de los hechos y castigar a los culpables,

\footnotetext{
147 Á. Solanes CoRella, «Contra la normalización de la ilegalidad...», op. cit., pp. 217-218.

148 STEDH núm. 22414/93, Chahal c. Reino Unido, de 15 de noviembre de 1993.

149 STEDH, Raza c. Bulgaria, de 11 de febrero de 2010.

150 E. CARmona Cuenca, «El derecho a un recurso efectivo...», op. cit., p. 578.
} 
pues no hay registro alguno de los hechos ${ }^{151}$. Esto supone, además, que sea imposible el efecto suspensivo del rechazo, pues no hay ningún procedimiento en que el extranjero pueda acreditar que están en riesgo su derecho a la vida o a la integridad. Por último, la laxitud de la regulación del rechazo en frontera y la falta de control jurisdiccional que permite implica una desorbitada facultad por parte del poder ejecutivo para fijar cuándo un extranjero es un peligro para la «seguridad nacional» (o ciudadana), además de no estar obligada a acreditar ninguna prueba de este peligro para rechazar al extranjero.

Esto ha sido confirmado por el TEDH en su Sentencia del caso N. D. y N. T. c. España, donde el TEDH condenó por unanimidad a España por vulneración del art. 13 como consecuencia de una devolución en caliente en que los demandantes no habían tenido asistencia de letrado ni intérprete, así como información sobre el derecho de asilo: circunstancias todas ellas que persisten en la regulación del rechazo en frontera.

\section{CONCLUSIONES}

1. La escasa regulación constitucional en materia de titularidad de derechos fundamentales y libertades públicas por los extranjeros ha llevado a la necesidad de un desarrollo jurisprudencial en este aspecto, estableciendo una clasificación tripartita de derechos atendiendo al criterio de la dignidad. Los extranjeros no son titulares de un derecho fundamental a entrar en España, pero, dentro de esta división, los derechos que se pueden ver afectados por el rechazo en frontera, como el derecho a la vida, a la libertad, a la integridad física y moral o a la tutela judicial efectiva, pertenecen a la categoría de derechos que corresponden por igual a españoles y extranjeros, por ser imprescindibles para garantizar la dignidad humana. El legislador puede establecer limitaciones a la titularidad de estos derechos por los extranjeros, pero en todo caso deberán respetar el conteni-

151 El Comité de los Derechos del Niño, en relación con esta materia, afirmó en el caso $D$. D. contra España que este país, junto a otros, ha creado una zona de excepción en la frontera en la que se suprimen las consecuencias legales no solo a través del impedimento a los extranjeros de llegar a las fronteras, sino evitando la recogida de pruebas y haciendo firmar a los individuos documentos en que renuncian a sus derechos. V. WRIEDT, «Push-backs Rejected: D. D. v. Spain and the rights of minors at EU borders», blog EU Inmigration and Asylum Law and Policy, European Center for Constitutional and Human Rights, 2019, disponible en bttp://eumigrationlawblog.eu/push-backs-rejected-d-d-v-spain-and-the-rights-ofminors-at-eu-borders/ (consultado el 26 de mayo de 2019). 
do esencial del mismo reconocido en la Constitución y en los Tratados Internacionales.

2. El supuesto fáctico de aplicación del rechazo en frontera ya estaba recogido en otro procedimiento previsto en la legislación de extranjería, el procedimiento de devolución [art. 58.3.b) LOEx], que es la actuación que debería poner en práctica la Administración cuando un extranjero pretende entrar ilegalmente en territorio español. Este procedimiento, a diferencia del rechazo en frontera, sí cumple todas las garantías requeridas por la Constitución y el Derecho internacional de los derechos humanos, tales como el procedimiento de identificación, asistencia jurídica y de intérprete, e información sobre la posibilidad de solicitar asilo. A esto se debe añadir que la misma función que cumplen ambas figuras permite aplicar las consideraciones jurisprudenciales sobre la naturaleza del procedimiento de devolución al rechazo en frontera, por lo que se puede considerar que el mismo es una medida sin naturaleza sancionatoria.

3. La práctica administrativa ilegal conocida popularmente como «devoluciones en caliente» se convirtió en un foco de atención nacional e internacional con los sucesos de la playa del Tarajal del 6 de febrero de 2014, lo que llevó al Ministerio del Interior a defender su legalidad con argumentos carentes de fundamento jurídico y a tratar de extenderle cobertura legal a través de la inclusión de la figura del «rechazo en frontera» en la LOEx a través de la LOPSC, ley que se estaba tramitando en las Cortes Generales en ese momento.

4. El procedimiento legislativo por el que se introdujo la regulación del rechazo en frontera en la LOEx a través de la LOPSC incurrió en numerosos vicios inconstitucionales. La facultad de enmienda legislativa se utilizó de forma abusiva, pues no existe correlación material entre la iniciativa legislativa (consistente en un conjunto de medidas para procurar la seguridad ciudadana) y el objeto de la enmienda (un régimen de expulsión de extranjeros desprovisto de procedimiento administrativo alguno). Esta desconexión material derivó, en primer lugar, en una ausencia de los dictámenes preceptivos sobre la figura del rechazo en fronte$\mathrm{ra}$, pues los mismos se producen antes del plazo de enmiendas, impidiendo a las instituciones competentes pronunciarse sobre una regulación tan diferente a la que se preveía en el Anteproyecto de Ley que les fue remitido; así como, en segundo lugar, en una privación de la sociedad civil de debatir públicamente este nuevo régimen legal. Por último, la legalización de las devoluciones en caliente constituye un supuesto del denominado fenómeno de «convalidación legislativa», pues se trata del otorga- 
miento de cobertura legal a una disposición o acto administrativo ilegal para dejar sin efectos prácticos una eventual o ya dictada sentencia judicial, amparando una práctica administrativa previa restrictiva de derechos individuales y privando a los ciudadanos de la posibilidad de una defensa efectiva.

5. El concepto operativo de frontera que ponía en práctica la Administración para llevar a cabo las devoluciones en caliente y que fue acogido implícitamente por la figura del rechazo en frontera choca frontalmente con las normas de Derecho internacional que rigen la demarcación de fronteras soberanas, pues son estas, y no la voluntad fluctuante del poder ejecutivo nacional, vulneradora del art. 9.3 CE, las que determinan las líneas fronterizas. Conforme a dichas normas y a la historia reciente, tanto las playas de Ceuta y Melilla como el espacio en que está construida la valla en su totalidad son territorio soberano español, pues lo que delimita la frontera española-marroquí es la valla exterior: toda persona que haya sobrepasado voluntariamente la misma se encuentra en territorio español y, por tanto, es sujeto de aplicación del ordenamiento español y europeo en su totalidad. Sin embargo, a pesar de que este concepto operativo de frontera es el que se ve reflejado en la puesta en práctica de la regulación del rechazo en frontera, se debe señalar que incluso la interpretación literal del mismo impediría su aplicación en los casos en que el extranjero trate de acceder por mar o ya haya traspasado la valla exterior. A mayor abundancia, se debe señalar que la jurisprudencia del TEDH plasmada en la Sentencia Hirsi Jamaa obliga a los Estados parte en el CEDH a salvaguardar los derechos reconocidos en el mismo a toda persona que esté bajo su jurisdicción, incluso si se hallan físicamente fuera de su territorio.

6. El rechazo en frontera, como acto administrativo no procedimental, no es un supuesto de ejecución forzosa, sino de coacción directa, que, como tal, debe respetar los principios de legalidad y de proporcionalidad. El principio de legalidad se ve conculcado puesto que el rechazo en frontera no respeta el límite implícito que constituyen los derechos fundamentales de los extranjeros; la laxitud de la regulación deja al arbitrio de la Administración la restricción de derechos fundamentales, incumpliendo el mandato del art. 53.1 CE; el supuesto fáctico de aplicación también está al arbitrio de la Administración, pues es ella la que determina, sin ningún criterio legal, cuándo concurre la urgencia que permite el uso de la coacción directa; y, finalmente, porque el rechazo en frontera constituye una desviación del poder, al suponer una actuación de las FCSE que vulnera los derechos y libertades de los ciudadanos, valores que son el verdadero fin 
de estas Fuerzas y Cuerpos de Seguridad. El principio de proporcionalidad también se ve vulnerado pues no respeta el principio de adecuación al no perseguir la seguridad ciudadana y vulnerar los derechos y libertades de los extranjeros, supuesto objetivo de la medida; tampoco cumple con principio de necesidad pues el mismo fin se podría conseguir de forma menos restrictiva con los derechos y libertades, aplicando el procedimiento de devolución del art. 58.3 LOEx; por último, vulnera el principio de proporcionalidad en sentido estricto al ser una medida contraria al principio favor libertatis, restringiendo derechos fundamentales de máxima importancia (como el derecho a la vida o a la tutela judicial efectiva) para tratar de impedir una mera infracción administrativa.

7. El rechazo en frontera vulnera diversas normas contenidas en el Derecho internacional de los derechos humanos que limitan la facultad del Estado para controlar los flujos migratorios. Una de estas normas es el principio de non-refoulement, que se ve infringido puesto que este régimen de expulsión de extranjeros permite la devolución de personas sin efectuar un procedimiento que les permita ser beneficiarios del estatuto de refugiado en caso de que sus derechos fundamentales estén amenazados en su país de origen. Asimismo, el rechazo en frontera conculca la prohibición de expulsiones colectivas, pues permite el rechazo de extranjeros sin llevar a cabo un examen individualizado de las circunstancias y sin permitir que aleguen sus argumentos para evitar la devolución. Por último, este rechazo producido sin ningún tipo de garantías es el que deriva en la vulneración de otro derecho humano, el derecho a un recurso efectivo, pues la falta de examen individual de la situación, la omisión de identificación y la ausencia de información sobre la posibilidad de pedir protección internacional supone la imposibilidad de interponer un recurso efectivo. 